\title{
The Impact of International Labor Standards: A Survey of Economic Theory*
}

\author{
Nirvikar Singh \\ Department of Economics \\ University of California, Santa Cruz \\ Santa Cruz, CA 95064
}

October 2001

\begin{abstract}
The main question guiding this study is whether international labor standards will benefit the poor, in particular, developing countries and the poor in those countries. We survey the theoretical literature on international labor standards, and give an overview of the analytical framework and main arguments provided in this literature. Among the situations in which a case for labor standards may arise are imperfections in labor markets, market power effects in international trade, and concerns that consumers, or individuals in general, may have about the working conditions or rights that other individuals enjoy. We emphasize the importance of making clear the value judgments being used, and discuss the different institutional issues that may arise in considering the implementation of labor standards. In general, while there are contexts in which promoting labor standards through some form of collective action is beneficial, we argue that such policies ought to be incorporated into a broader perspective on well-being, and a package of policies that can promote the well-being of the poor.
\end{abstract}

\footnotetext{
* This study is part of a larger project on international labor standards, initiated and funded by the Swedish Ministry of Foreign Affairs and the Expert Group on Development Issues, Sweden. I am grateful to Lisa Román of the Department of International Co-operation, Swedish Ministry of Foreign Affairs, as well as Henrik Horn and Kaushik Basu, members of the reference group for the project, for extremely helpful comments and guidance. T.N. Srinivasan and Tore Ellingsen, the discussants of this paper at the Seminar on International Labor Standards in Stockholm, August 2001, made excellent comments and suggestions that I have acknowledged in the present version, but have not been able to fully incorporate into the present study. I am also grateful to Kimberly Elliott, Robert Fairlie, Michael Hutchison and John Isbister for comments received when I presented a preliminary version of these ideas at a workshop of the Santa Cruz Center for International Economics. I am solely responsible for all errors and omissions, and the views expressed here are not those of any of the individuals or organizations mentioned.
} 


\title{
The Impact of International Labor Standards: A Survey of Economic Theory
}

\author{
Nirvikar Singh \\ Department of Economics \\ University of California, Santa Cruz \\ Santa Cruz, CA 95064
}

\section{Introduction}

The main question guiding this study is whether international labor standards will benefit the poor, in particular, developing countries and the poor in those countries. We survey the theoretical literature on international labor standards, and give an overview of the analytical framework and main arguments provided in this literature. Among the situations in which a case for labor standards may arise are imperfections in labor markets, market power effects in international trade, and concerns that consumers or general individuals may have about the working conditions or rights that other individuals enjoy. We emphasize the importance of making clear the value judgments being used, and discuss the different institutional issues that may arise in considering the implementation of labor standards. In general, while there are contexts in which promoting labor standards through some form of collective action is beneficial, we argue that such policies ought to be incorporated into a broader perspective on well-being, and a package of policies that can promote the well-being of the poor.

While there is a large literature on international labor standards, much of its focus has been on evaluating the appropriateness of linking labor standards with trade. Excellent recent surveys include those of Brown, Deardorff and Stern (1996), Golub (1997), and Maskus (1997). This survey goes back to basics, in some respects, and reviews some of the key economic arguments in favor of labor standards. We also emphasize the welfare judgments that are involved in debates about labor standards, and how to think about them rigorously. We do examine some of the links to international trade, and update previous surveys in this respect. We gather together some of the 
political economy and, more broadly, collective action issues that arise in considering international labor standards. Most importantly, perhaps, we follow some recent writings by development economists such as Pranab Bardhan and Kaushik Basu in tying the issue of international labor standards to broader perspectives on development and issues of helping the poor.

The structure of the paper is as follows. In Section 2, we lay out some of the practical ways in which concerns about workers rights and working conditions have been delineated for policy discussion. Doing so highlights the importance of value judgments and normative concerns in this sphere. Because rights are an important component of how labor standards are framed in policy debates, we therefore go on to a discussion of how rankings of processes or rights as well as outcomes can be combined, and the implications of such an approach. This more general approach helps in bringing out the potential conflicts or tradeoffs between outcomes and processes, and therefore in evaluating the impacts of labor standards.

In Section 3, we examine several possible labor market problems, what their consequences might be in terms of worker welfare, how to evaluate them in terms of labor market processes, and finally, what the impacts might be of different interventions that come under the broad heading of "labor standards". Among the issues we consider are imperfect competition due to market power, lack of information, and survival constraints. In conducting this review, we connect some innovative new analyses to the labor standards literature, such as conflicts between the right of voluntary contracting and welfare outcomes for workers. We clarify the nature of these trade-offs. We also clarify some of the modeling assumptions that have been used by other authors with respect to labor market competition, and suggest some generalizations to incorporate working conditions into conventional models such as that of monopsony in the labor market.

In Section 4, we consider a range of economic models that place international and domestic labor standards in the context of the world economy with international trade. We describe how the standard competitive model of international trade can be used to evaluate the impact of labor standards, and the comparison of international labor 
standards with other policies, including purely domestic interventions. We examine models in which countries have "pricing power" in international markets, so that international terms of trade can be affected by domestic choices. We examine possible distributional impacts of trade in developed and developing countries, either in terms of the effects on labor versus capital, or on unskilled versus skilled labor. When labor standards are chosen domestically, their choice may be distorted by the potential for influencing the terms-of-trade, and we review recent analysis that suggests a possible method for integrating international labor standards with international trade negotiations. We consider the general case of various international coordination problems, typically clustered under the heading of "races to the bottom". We review several different possibilities here, including new analysis of such potential problems among developing country exporters. This model fails to support the use of trade sanctions by developed countries as a way of improving labor standards and welfare in developing countries.

In Section 5, we examine the rather contentious questions of "who decides and how?" in the context of international labor standards. We begin with an analysis of issues raised by the possibility that consumers in one country may care about the methods used to produce the goods that they consume, when those goods are imported from abroad. We develop the argument that such consumers ought to be willing to pay more for products that are made according to "acceptable" labor standards, and we discuss the practical problems that might arise in implementing such a solution in the market, including issues of lack of information and effective monitoring. The case where concerns over another country's working conditions and worker rights are not be tied to consumption of imports raises a public good problem, and we consider various collective action problems and possible institutional solutions that might arise. We discuss the possibility that groups with different interests might cooperate on international labor standards, and we examine the issue of where to draw the line in cases where there are spillovers in concerns of citizens of one country to those of another country.

Finally, in Section 6, we consider the impact of international labor standards on the poor. We examine the case that international labor standards can end up hurting those they are supposed to help, unless they are part of a broader policy package. We link this 
to an argument that the proper concern, even where processes matter as well as outcomes, is with a more basic set of capabilities and rights than is typically encompassed by proponents of international labor standards. Labor standards may certainly have a role to play, but they must be put in context, both conceptually and in terms of implementation. We also review work on the links between the markets for education, credit and labor, and examined the role that labor standards might play. Such concerns are particularly important for child labor, but apply more broadly as well. We also examine some possible connections between international labor standards, technological progress and economic growth, but we find no obvious theoretical case in which imposing labor standards on poorer countries will help their long-run growth. On the other hand, we argue that policies that promote basic nutrition and health, and broader access to education and credit are likely to help growth, as well as having intrinsic benefits. Labor standards may well be a component of such policies, but must be implemented in context. Section 7 is a concluding section that reviews the paper and summarizes our main conclusions.

\section{Delineating Labor Standards}

Labor standards can be seen as falling into two broad categories. The first category specifies standards as procedural rights, emphasizing that individuals or groups may do or not do certain things without penalty. The second category specifies standards in terms of outcomes, specifying that individuals or groups should be able to enjoy certain minimum levels of income or consumption in particular dimensions. These two categories overlap. They are also connected respectively to two somewhat different ethical views, which might be, albeit somewhat simplistically, characterized as the "rights" and "welfarist" perspectives. We shall discuss these theoretical issues after we have provided some practical examples of labor standards. We shall not go at all into the history and evolution of current formulations of international labor standards, since that task is performed in Engerman (2001), which forms part of the same project as this paper. 


\subsection{Examples of Current Labor Standards}

Portes (1990) provides a classification of different kinds of labor standards, which is summarized in Table 1 (taken from Maskus, 1997). The first category encompasses fundamental human rights, as recognized in various UN declarations. The second category, that of civic rights, deals with workers' positions with respect to their employers. In some respects, these rights are derived from basic rights (e.g., protection from physical coercion is the basis for free association and expression), and are related by involving some aspect of free choice. However, in practice the boundaries of these civic rights are often much less clear than those of basic rights. For example, it may be considered quite acceptable that employers are able to fire and replace striking workers, and this places practical limits on the right to collective representation. Hence, almost from the start, we begin to encounter practical problems with what, at first sight, seem to be very straightforward and obvious virtues. Therefore we will discuss matters such as hierarchies of rights, and the relationship of rights to welfare later in this section and at other points in the paper.

Survival and security rights are the third and fourth categories of rights listed in Table 1. They relate to conditions of work that affect worker well being, but do not necessarily directly impact freedom of choice. One might argue that being fully informed about job hazards is as fundamental a right as those in the first two categories, and, indeed, a choice that is uninformed as a result of deliberate concealment of information is hardly a free choice. Again, we postpone a more detailed discussion of such issues. Note, also, that the standards in the third and fourth categories include economic outcomes pertaining to working conditions, such as "a living wage", "limited hours of work" and various kinds of compensation, but they are couched in terms of the language of rights. 
Table 1: Labor Standards as Rights

\begin{tabular}{|c|c|}
\hline Type & Examples \\
\hline Basic Rights & $\begin{array}{l}\text { Right against involuntary servitude } \\
\text { Right against physical coercion } \\
\text { Right to compete without discrimination } \\
\text { Right against exploitative use of child labor }\end{array}$ \\
\hline Civic Rights & $\begin{array}{l}\text { Right to free association } \\
\text { Right to collective representation } \\
\text { Right to free expression of grievances }\end{array}$ \\
\hline Survival Rights & $\begin{array}{l}\text { Right to a living wage } \\
\text { Right to full information about hazards of job conditions } \\
\text { Right to accident compensation } \\
\text { Right to limited hours of work }\end{array}$ \\
\hline Security Rights & $\begin{array}{l}\text { Right against arbitrary dismissal } \\
\text { Right to retirement compensation } \\
\text { Right to survivors' compensation }\end{array}$ \\
\hline
\end{tabular}

Source: Maskus (1997), Portes (1990)

Perhaps the best-known expression of a fundamental subset of labor standards is the Organisation for Economic Cooperation and Development's (OECD, 1996) set of core labor standards (CLS), which also corresponds closely with the International Labour Organisation's (ILO) core standards. These are summarized as follows:

1. Prohibition of slavery and compulsory labor, such as bonded labor

2. Nondiscrimination in employment among genders, ethnic groups, etc.

3. Prohibition of exploitative forms of child labor

4. Freedom of association (the right to organize workers' groups)

5. Freedom of collective bargaining over working conditions

We can see that this list corresponds quite closely to the first two categories in Table 1. The second pair of categories in Table 1 is totally omitted, however, from this OECD CLS list. 
In contrast, the United States' formulation of labor standards, as expressed in various legislation related to international trade, gives working conditions a more prominent role. The following list is taken from Golub (1997), and represents a condensation of a more detailed list provided in the appendix of Brown, Deardorff and Stern (1996):

1. Freedom of association

2. The right to organize and bargain collectively

3. Prohibition on forced or compulsory labor

4. A minimum age for the employment of children

5. Guarantee of acceptable working conditions (possibly including maximum hours per week, a weekly rest period, limits to work by young persons, a minimum wage, minimum workplace safety and health standards, and elimination of employment discrimination)

Finally, Engerman (2001) provides a categorization of labor standards that very much takes an economist's perspective. He divides standards into three groups:

1. Labor market conditions, such as wages and hours, with different provisions according to age and gender

2. Working conditions pertaining to safety and sanitation

3. The general range of arrangements between labor and management, including general rights as well as some contractual arrangements

It can be seen that Engerman's third category includes most of the general rights that are spelled out in detail in the OECD and US lists.

Both the OECD and US lists, as given above, are appealing in terms of the ideals that they express. Both lists are dominated by considerations of rights and processes, though the working conditions category in the US list includes a mixture of process and outcome concerns. More recently, the US has endorsed the ILO/OECD list, leaving out working conditions, except for nondiscrimination. However, despite this convergence, 
and as we have noted, the details can be quite problematic. Conflicts can arise between different ideals. Defining the practical limits of various rights can be extremely difficult. Since actual policies will require working out such details, it is important to examine the differing justifications for various international labor standards, as well as their potential impacts. It is not clear, for example, that even the two lists combined cover all fundamental issues. For example, neither list explicitly mentions the right to full information about job hazards (pertaining to process rather than outcome), which Fields (1995) has argued is a fundamental right.

\subsection{Framing Labor Standards}

We have alluded to outcome versus process-based standards, and to rights-based versus welfarist ethical perspectives. We next discuss these theoretical issues in greater detail. While some abstraction is involved, it is essential because it helps to clarify some of the bases for disagreement in practical debates on labor standards.

We begin with a discussion of rights and welfare. ${ }^{1}$ Standard welfare economics focuses only on the consequences of institutions and policy for individuals who make up a society (however we choose to define it - community, nation, or globe, for example ${ }^{2}$ ). This consequentialist approach has two components. First, the welfare of individuals is typically taken to depend only on their consumption of material goods and services. Individuals are assumed to have rankings over all different possible bundles of such goods and services (e.g., $3 \mathrm{lb}$. of rice for 4 hours of work in a day is preferred to $2 \mathrm{lb}$. of rice for 3 hours of work). These rankings, if well behaved enough, can be replaced by utility functions, which are simply numerical indices of preference ("higher utility" is

\footnotetext{
${ }^{1}$ Our treatment of this deep area with an enormous literature will have to be brief. Some of the important writers on this topic include Kenneth Arrow, James Buchanan, Robert Nozick, Prasanta Pattanaik, Amartya Sen, Robert Sugden and Kotaro Suzumura. Selected works that provide more references to the literature include Pattanaik (1999), Sen (1985a, b) and Suzumura (1999).

${ }^{2}$ T.N. Srinivasan, in his comments, infers that this generality of the abstract theory, in terms of its applicability to different societies, means that I think "it does not matter ...how a society came to be established and whether it is the community, nation or the globe." As a reading of Section 5.3 will show, this is not at all the case. His comments on restricted domains of preferences are, nevertheless, quite useful.
} 
equivalent to "better preferred"). Actually, consequentialism can be broader, allowing one individual's utility to depend on the outcomes of all members of society.

The second aspect of a consequentialist approach refers to the evaluation of the welfare of members of a society in the aggregate. Again, a consequentialist is only concerned with the preference rankings or utility functions of the individual members of society in evaluating aggregate welfare. The application of consequentialism to such concerns as evaluating individual welfare and the overall welfare of a group can be termed "welfarism."

To put the above ideas in context, consider the various rights listed earlier when we gave example lists of labor standards. For example, the right to free association is included as a fundamental or core standard. A consequentialist or welfarist position would be that such a right should not matter in itself, but only if it affects the outcomes for the individual. These may be explicitly material, e.g., if they enable the individual to bargain more effectively with an employer, or gather information about job safety from fellow workers. They may also be purely "psychological", such as the pleasure a worker may derive from exchanging banter with colleagues. Ultimately what matters is if the worker through free association is thereby able to make choices that increase her or his utility.

Lindbeck (1988) and Sen (1997) have articulated an alternative view. They suggest that the opportunities available to an individual matter, beyond consideration of the value of the best opportunities. In other words, the size of the choice set, or the freedom to choose from a bigger set, has intrinsic value. This concern with opportunities, however, seems to unnecessarily mix the general benefits of choice with the issue of the size of the choice set. Being freer to choose, even actions that are harmful to oneself, can instead be viewed as one kind of procedural consideration. It is procedural matters, therefore, that are central to the "rights" perspective. Aside from freedom, fairness may be the other broad category of procedural consideration that matters.

At this point, we may note that the connection between process-based labor standards and rights-based ethical approaches is close but not perfect. A procedural 
standard may be justified purely because we care about the right to certain kinds of freedom and fairness, or it may be justified on outcome-based grounds. For example, in the former case, the right to be fully informed about job risks is desirable irrespective of whether it has any positive or negative impact on the worker's behavior or utility (he may just feel more anxious, without anything else changing). In the latter perspective, full information is good only if it improves the worker's well being - he directly or indirectly enjoys greater utility.

Having sketched some of the essentials of the welfarist and rights approaches to evaluating policy, we explore some of the possible conflicts between these approaches, and the extent to which one can find pragmatic compromises that will allow one to go forward with practical decision-making. If there were no conflict between the two approaches, our task would be much simpler. However, it is very easy to construct examples where valuing procedures or rights conflicts with consequentialist or welfarist approaches. This point was first made in general by Sen (1970), and we illustrate it with an example from Pattanaik (1999).

In the example, there are two individuals, say Adam and Bob, who each can choose whether to wear a red or a white shirt. Their rankings of the overall choice by both of them are shown in Table 2, below. The first element of each pair is Adam's shirt color choice, while the second is Bob's choice. The columns give each person's ranking in descending order, so that a combination that is higher in the column is preferable to one that is lower. Each person prefers to wear a white shirt, whatever the other person chooses to wear. For example, Bob prefers white to red if Adam chooses red (top two elements of Bob's column), and also if Adam chooses white (bottom two elements of Bob's column). Note that there is some degree of concern for others' consumption or choices in these preferences. Thus, whatever Adam wears (white or red), he prefers that Bob wear red. These preferences might be considered to be "meddlesome", but they seem to be so in a mild sort of way. In any case, they reflect each person's true rankings. 
Table 2: Preferences that Lead to a Conflict between Rights and Outcomes

\begin{tabular}{cc}
\hline Adam's Ranking & Bob's Ranking \\
\hline (White, Red) & (Red, White) \\
(Red, Red) & (Red, Red) \\
(White, White) & (White, White) \\
(Red, White) & (White, Red) \\
\hline
\end{tabular}

The problem that arises in this example is as follows. If one believes that rights such as freedom over personal choices matter, then clearly Adam and Bob should be allowed to make their personal choices, and each will choose to wear white, irrespective of the other's choice. However, Adam and Bob would unanimously agree that (Red, Red) is a better outcome than (White, White). A consequentialist would be obliged to say that the former outcome is therefore superior, even though it overrides the free choices of the two individuals. Thus we have a basic conflict between the rights and welfarist perspectives.

One way around the conflict illustrated by the above example is to allow individuals to have rankings over processes as well as over outcomes. To elucidate this in the context of the previous example, suppose there are two possible institutions, one in which Adam and Bob are both empowered to choose the colors of their own shirts, and another in which the shirt colors are specified collectively or cooperatively. Let us denote these two cases by the letters I (for individualistic) and C. Then if Adam and Bob both care about strongly enough about their individual rights, each may prefer the outcomeprocess combination (White, White, I) to the combination (Red, Red, C), even though the outcome (Red, Red) is unanimously preferred. ${ }^{3}$

\footnotetext{
${ }^{3}$ More formally, procedural institutions can be modeled as game forms, which specify the set of individual actors, their admissible strategy sets, a set of feasible outcomes, and an outcome function that maps strategy profiles to outcomes. The "rules of the game", such as the admissible strategy sets or outcome function, may result in certain strategies being excluded (denying me a job because of my race) or punished (legal damages against someone who discriminates in hiring on the basis of race), as ways of capturing rights.
} 
Allowing individuals to care about rights or processes in their rankings at least partially resolves the tension between the rights-based and welfarist perspectives. If these extended rankings are well behaved enough, individuals still may have utility indexes that indicate their welfare, but utility now depends on processes as well as the outcomes. This expanded approach to evaluating social situations is important in general, but is particularly useful in clarifying the manner in which an important subset of labor standards is framed, since they emphasize basic rights.

While the right to wear the color of shirt one pleases, used in the example, may seem trivial, it is, of course, illustrative of "[t]he desire to be governed by myself...as deep a wish as that of a free area for action, and perhaps historically older."4 Other examples of rights that may be considered important include rights to non-discrimination on the basis of race or gender, the right to practice one's religion, the right not to be imprisoned without due legal process, the right to an education, and so on. Some workplace rights might be deemed to fall easily within the broad class of basic rights: rights to a safe workplace and free association are possible examples. Other rights, such as those to a job or to a 'living wage' may be considered to be less fundamental or absolute. On the other hand, the broader right to the basic means of existence might well be ranked as a fundamental right. While labor standards often focus on rights, we wish to suggest that, rather than de-emphasizing rights, a broader approach to rights is more appropriate: promoting the broader right to the basic means of existence may be more fruitful than focusing on the right to a job or a 'living wage'. This point will be more fully developed in the penultimate section of the paper.

We have already noted the potential conflict between the rights approach and pure consequentialism. This issue may be more serious than just the color of the shirt one wears. If there are substantial losses in efficiency that result from enforcing some rights, such as can arise when entitlements create moral hazard or other incentive problems, then we may be willing to sacrifice some rights in some circumstances. This is precisely what the extended ranking of outcome-process combinations allows - individuals may details. 
explicitly incorporate tradeoffs between outcomes and procedures in their judgments. Recognizing these tradeoffs explicitly may sometimes be unpleasant, but it can help to clarify debates over the appropriate nature and enforcement of labor standards.

A further issue that must also be called out in more detail is that different rights may conflict with each other: they are rarely completely absolute. For example, the right to free expression is limited by the rights of others not to be injured, including by such free expression. Such conflicts may ultimately boil down to tradeoffs between rights and outcomes, but they may also be pure tradeoffs between different rights. For example, the right to free expression may conflict with someone else's right to be fully informed, if the free expression involves withholding or distorting information, even if that distortion causes no material or psychological harm. ${ }^{5}$

Typically, rights conflicts will be interpersonal (one person's rights conflict with another's), though one can concoct examples where one person exercising a right may harm his ability to enjoy another right. While the ranking of outcome-process combinations solves the problem of single-person rights tradeoffs, the aggregation of individual rankings into a social ranking is required to resolve interpersonal rights tradeoffs. This is a deep issue that also must be faced up to in considering international labor standards. When we have a list of labor rights, how are different rights in the list to be weighed against one another, or ordered in terms of the degree to which they are fundamental? Furthermore, how are these judgments to be made when other rights - not just labor-related rights - are included in the mix? One may respond by throwing up one's hands and saying that only consequences matter, but that does not resolve these issues, which, while abstract, underlie the theoretical and practical debates about labor standards.

\footnotetext{
${ }_{5}^{4}$ Berlin (1969), pp. 15-16, quoted in Suzumura (1999).

${ }^{5}$ One can argue that if there is no harm, then the conflict of rights does not matter, but then this is a consequentialist judgment.
} 


\section{Labor Markets and Labor Standards}

Having provided a brief discussion of what labor standards mean in practice, and how they may be viewed within a general normative perspective, we turn to examining more specific justifications or rationales for various kinds of labor standards. Our starting point in this section is standard models of labor markets. We outline the standard model of competition, consider variants of this model, and explore how market failures may arise, creating a case for government intervention in the form of labor standards. This analysis is couched in familiar welfarist terms. Aside from market failures, a case for government intervention in the labor market may be made on grounds of concern for equity. This, too, fits into the welfarist approach. In both these cases, one may also question the ability of governments to effectively achieve objectives of increased efficiency or equity through their interventions - we discuss this briefly as well. Finally, in this section we examine issues that intersect with concerns for rights, in particular the right to voluntarily engage in labor contracts. As we have explained in the previous section, welfarist concerns are not thereby excluded, but tradeoffs between processes and outcomes are more explicitly recognized.

\subsection{The Basic Competitive Model}

In the standard model of competitive labor markets, workers and firms are small relative to the market, and take market conditions, particularly the wage, as given. Workers can specify a quantity of labor they will supply at each possible market wage rate, while firms can likewise specify a quantity of labor they will demand at each possible wage rate. The market wage rate itself is determined by the condition that there be no excess supply or demand in the labor market. This is illustrated in Figure 1, where $w^{c}$ is the competitive equilibrium market wage rate, determined by the equality of quantities supplied and demanded (point A). 


\section{Figure 1: Competitive Equilibrium in the Labor Market}

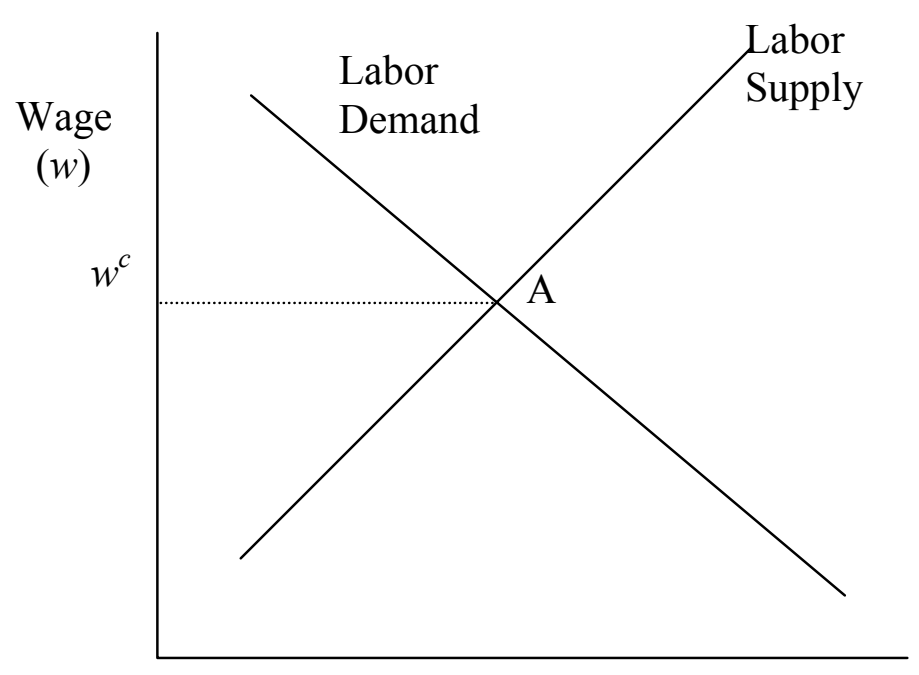

Hours worked $(h)$

The supply curve of labor in Figure 1 is derived from the worker's simultaneous utility-maximizing choices of market-purchased consumption goods and leisure - the decision on the number of hours of work to supply is equivalently the decision on the number of hours of leisure to give up for work. The worker's utility may also be affected by a range of nonpecuniary job characteristics, which we shall lump together as "working conditions", and which will be a major focus of the discussion of labor standards in this section. The demand curve for labor in Figure 1 comes from profit maximization by the firm, which decides how much labor, capital and any other inputs to employ, taking all output and input prices as market-determined. The firm knows its technological possibilities perfectly. We assume for the moment that working conditions are fixed by technological factors, but they may affect the productivity of the firm's inputs, and labor in particular. ${ }^{6}$

It is useful to relate this simple model to Engerman's three-part classification of labor standards. First, wages and hours here are outcomes determined by the competitive

\footnotetext{
${ }^{6}$ Appendix 1 provides a simple formalization of the model, which will be used to provide a parallel formal treatment of some of the issues to be tackled later in the main body of the paper.
} 
market process, without any other restraint. Second are working conditions, such as safety and sanitation. Third are the conditions determining labor-management interactions: here these involve atomistic agents, with no bargaining power. In this outcome, there is no efficiency problem, in the sense that, taking all other economic conditions as given, no intervention in this market will improve the allocation of resources. We have said nothing so far about working conditions, taking them to be exogenously given, and therefore there is not yet any efficiency issue to be tackled with respect to working conditions.

However, it is possible that we may still find the competitive equilibrium of Figure 1 to be unsatisfactory on equity grounds, because we think that the outcome, either in terms of the workers' wage, or her total income, or her overall utility is too low. The theoretical solution to that problem is lump-sum transfers of endowments, as T.N. Srinivasan points out in his comments. Often, however, informational and political constraints (touched on in Sections 5 and 6) make such policies infeasible in practice, and other, second-best, remedies are used. For example, a minimum wage above the competitive wage will benefit some of the workers in this situation, but hurt others, as firms reduce the hiring of labor, in numbers, hours or both. One might, alternatively, allow workers to bargain collectively with firms. That solution might also be preferred on rights-based grounds. The outcome in that case, however, will also be somewhat ambiguous effects on the welfare of the workers, as firms cut back on hiring. In both cases, the effect on the efficiency of resource allocation is negative (as Srinivasan implicitly emphasizes in his comments). One policy that may not have negative efficiency effects suggests itself if workers' productivity is inefficiently low. It may be best to raise workers' income and utility by making it possible to increase their productivity. This is a simple point, but one that will crop up repeatedly in our discussion as a counterpoint to the too ready imposition of labor standards. 


\subsection{Firms Decide Working Conditions}

We have presented the most basic competitive story, and we have not given job characteristics or working conditions any role so far, except to allow them to exogenously affect output as well as utility. The justification for allowing working conditions to affect output is that more pleasant or safer working conditions may affect the productivity of workers, presumably positively. Therefore, we next consider the case where the firm can make choices that affect working conditions. For simplicity, we can assume that while there may be many dimensions of job characteristics, these can be aggregated into a one dimensional index of working conditions that affects output - nothing essential is lost with this assumption.

Realistically, providing better working conditions will also cost the firm more, at least beyond some point - some minimum level of working conditions might be technologically determined, and incorporated in some fixed cost term. The firm will then choose the level of working conditions so that the marginal benefit in terms of higher output equals the marginal cost of improving working conditions, provided that such a possibility exists. Otherwise, if the marginal benefit is always too low, the firm will choose the minimum level of working conditions determined by technological constraints (see Appendix 2). In particular, if there is no impact of working conditions on productivity, then the firm will always choose the minimum feasible level of working conditions, even if workers benefit (derive higher utility) from better working conditions. Even in the case where the firm chooses working conditions above the minimum level, its calculations ignore the benefits to workers, and therefore the chosen level of working conditions is not socially efficient.

The problem of suboptimal working conditions that we have just outlined arises because there is no mechanism whereby the workers' desire for better working conditions is incorporated into the firm's choice. There are several plausible ways to introduce this possibility. For example, workers might be able to purchase improved working conditions in some way. If improved working conditions do not affect output, and if workers can choose their individual levels of working conditions through purchase on 
competitive markets (e.g., safety glasses, protective clothing, etc.), then this would be efficient (see Appendix 2). However, this is a very limited solution, precisely because neither requirement is likely to be met in practice.

It is more realistic to assume that firms explicitly or implicitly specify working conditions, along with the wages for different jobs. Workers can then evaluate the combinations of wages and working conditions that are available, thus allowing their own benefits from better working conditions to be introduced into their decision-making, and firms' responses. Firms will, of course, take account of their own benefits from better working conditions, in terms of higher productivity. The difference from the basic competitive model is that firms do not take wages as determined by competitive market forces. Instead they make offers of wage-working conditions pairs. Competition may still occur, in the form of free entry that drives firms' profits to zero. Alternatively, one can consider the case where firms do not compete, but workers instead receive their "reservation utility", the minimum utility from a job that the worker will accept, rather than choosing an alternative occupation. Both formulations are possible under this approach, which is well known as the theory of equalizing differences or compensating differentials. $^{7}$

We can illustrate the workings of a labor market with equalizing differences. In order to do so, we assume that firms and workers have already determined what their best choices of other variables (labor and capital levels for firms, hours worked and consumption decisions for workers) will be, for any given wages and working conditions. Thus we can focus on market determination of wages and working conditions. Suppose that there are many firms and many potential workers. The profit of a typical firm, $i$, depends on the combination $(w, s)$ of wages and working conditions that it offers. Similarly, the utility of a typical worker, $j$, also depends on the combination $(w, s)$ that she accepts. A firm will make higher profits whenever $w$ or $s$ is lower, other things equal, while a worker will be better off with a higher $w$ or $s$, other things equal. If firms are competitive due to free entry (which is most in keeping with the basic competitive 
model), then each firm must make zero profits in the competitive equilibrium. In Figure2, we show the combinations $(w, s)$ that give two different firms zero profits. The thicker line shows the upper envelope curve for all firms' zero-profit combinations: these are the best combinations of wages and working conditions that the market can provide. Finally, there are two curves showing combinations $(w, s)$ that give the workers their best choices among those the market can provide.

\section{Figure 2: A Labor Market with Compensating Differentials}

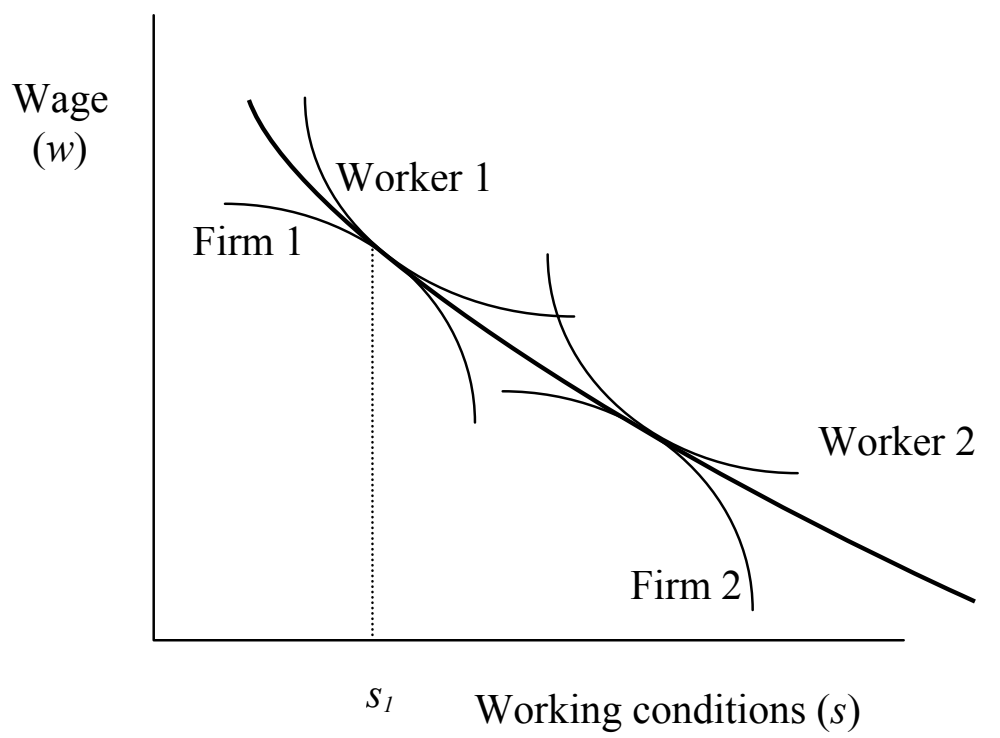

As we have constructed Figure 2, worker 1 is best off working for firm 1. Worker 2 , who prefers better working conditions, finds them with firm 2 , but at a wage that is lower. Alternatively, we can say that worker 1 receives a compensating differential of a higher wage for tolerating worse working conditions. In fact, worker 2 would also have to be compensated with a higher wage for worse working conditions than her choice, but that would require combinations of $(w, s)$ that no firm can provide and still break even. The main point here is that the outcome is efficient, in the sense that resources cannot be

\footnotetext{
${ }^{7}$ The theory is comprehensively surveyed in Rosen (1986), who describes its origins in the writings of Adam Smith. A significant theoretical analysis in the context of job safety is by Thaler and Rosen (1975). Dickens (1984) also discusses various aspects of working conditions in the context of this approach.
} 
reallocated to make any worker better off, without hurting some other worker. ${ }^{8}$ From a strict consequentialist perspective, therefore, there is no room here for labor standards.

One could still take the position that worker 1 has a right to some minimum level of working conditions. In this case, imposing a minimum level of working conditions above $s_{1}$ will make worker 1 worse off in terms of her ranking over outcomes, because she will be forced to accept a less-preferred combination $(w, s)$, given the constrained choice of combinations offered by the market. Hence there is the kind of conflict between rights and welfare that we have discussed in Section 2. If workers have extended rankings over combinations and procedures, they may agree that procedures that allow workers to accept jobs with poor working conditions are to be ruled out. In this case, how this aggregation of individual rankings over outcomes and processes is made becomes crucial. Therefore this is an issue we will return to in greater detail in Section 5.

There are two further points to consider in the model of compensating differentials. First, we have assumed that firms' profits are driven down to zero by competitive entry. This may be an unrealistic assumption. In many cases, especially in developing countries, workers may instead be competing for jobs in a manner that pushes them down to their reservation utilities - measures of how well off they would be in alternative occupations (working on the family farm, being a street vendor, or perhaps even begging). ${ }^{9}$ In this case, the thick line in Figure 2 can be interpreted as combinations that give workers reservation utilities. In the market equilibrium, firms now make positive profits. The market outcome is still allocationally efficient, but it may be considered undesirable on distributional grounds.

In theory, a redistributional policy may work here. If worker 1 is in an industry that is inherently unsafe, for example, imposing a higher standard of working conditions while requiring the wage to be maintained at the same level would make the worker better off at the expense of the firm: there is room to do so because the firm is making a positive profit. The combination $(w, s)$ that results from this policy creates an allocational

\footnotetext{
${ }^{8}$ A formal mathematical analysis of the situation illustrated in Figure 2 is sketched in Appendix 2.
} 
inefficiency, but it improves the equity of outcomes. ${ }^{10}$ There are also practical issues of enforcement or implementation, but these exist with any policy intervention. If the wage condition is not included, however, the firm's response to a higher safety standard would be to lower the wage it pays, reducing the worker to her reservation utility again.

The second point to be added to the discussion of the compensating differential model concerns the hiring of multiple workers by a firm. If there are many workers and many firms in many industries, the outcome will be much like Figure 2. Firm 1 will simply be the representative firm in its industry, and each such firm will be able to hire as many workers as it wants at the combination $(w, s)$ that is shown as chosen by worker 1 . Suppose, instead, that there are only two industries, with technological possibilities represented by the zero profit combinations available to firms 1 and 2 in Figure 2. A worker with preferred tradeoffs over wages and working conditions that are intermediate between workers 1 and 2 will not be able to select a point on the thick line, but will instead have to select a combination $(w, s)$ that is on one of the two firms' zero-profit curves. This assumes that a firm can offer different levels of working conditions to different workers. It may be that the firm has to choose the same level of working conditions for all its workers (the air quality in the factory, for example). Then the firm has to balance the preferences of its different workers in making its offers compensating differentials cannot be perfect in this case. The case where working conditions are a good that is jointly consumed by workers (and by the firm if it enjoys higher productivity from better conditions) raises some significant new issues that are taken up in the next subsection.

\footnotetext{
${ }^{9}$ In fact, as T.N. Srinivasan has emphasized in his comment, a large fraction, even a majority, of the work force in developing countries is self-employed. In such cases, we can think of the worker as owning the firm, as well as being the sole employee, and the efficiency argument following Figure 2 applies.

${ }^{10}$ Presumably the firm is owned by better-off individuals, so a reduction in the firm's profits is truly a redistribution from richer to poorer. The allocational inefficiency may or may not be of concern - while lump-sum taxes are the nondistortionary ideal, they are practically impossible, and many kinds of distortionary policies are used in practice to achieve redistribution. The practical policy question is typically how to minimize overall inefficiencies.
} 


\subsection{Working Conditions as a Public Good}

To the extent that the same working conditions are shared by all workers in a firm, and those conditions affect their well-being directly, as well as their productivity, working conditions have the character of a public good. The essence of a public good is that it is shareable or non-rival: in other words, one worker's consumption does not reduce the amount available for other workers to consume. Clean air in a factory, safety information, and general safety procedures are examples that fit this category quite well. A pure public good is also non-excludable, so, for example, if clean air is provided in a building to some workers, other workers in the building cannot be excluded from also enjoying the clean air.

If there is some exclusion mechanism, even partial, a public good can be termed a club good, with the analogy being to a club where membership is required, but all members enjoy the same amenities. Public goods and club goods may also be subject to congestion effects, in which case they are partly like private goods: one person's consumption tends to reduce the amount available for others. All these ideas are surveyed in, for example, Cornes and Sandler (1986).

Public goods pose a general problem for market-based resource allocation, because they create incentives for individual to not reveal their true benefit from consuming the public good, and therefore to not pay a share of the cost that reflects their true benefit. ${ }^{11}$ This occurs because an individual can benefit from the public good if others are willing to pay for it. This problem is well known as the "free-rider" problem, and it results in underprovision of the public good relative to the efficient level, as measured by standard ways of assessing overall welfare. It does not arise in the case of private goods because there is no shareability or jointness in consumption. While several aspects of working conditions have the character of public goods, the implications of this have not been explored in analyses of regulation of working conditions such as those of

\footnotetext{
${ }^{11}$ This problem of revelation of true benefits applies even if the public good provider (the firm in this case) can tax the beneficiaries - only quite complex schemes can implement efficient levels of provision: see Cornes and Sandler (1986) for more detail. I am grateful to Kaushik Basu for helping me clarify this point.
} 
Dickens (1984) and Brown, Deardorff and Stern (1996). We therefore provide some discussion below.

Consider first the case where there is just one worker, who benefits from better working conditions. Thus better working conditions increase her utility (her index of material well-being). Furthermore, the same working conditions simultaneously affect the worker's productivity, and hence the profit of the firm (before costs of providing working conditions are factored in). The optimal provision of working conditions requires that the sum of the marginal benefits of the worker and the firm be equated to the marginal cost of improving working conditions at the best possible level of those conditions. ${ }^{12}$ If the firm and worker can cooperate honestly, they can achieve this best level of working conditions. However, each has an incentive to let the other pay, and free ride, at least partially. This "noncooperative behavior" will lead to underprovision of working conditions, that is, they will be worse than the efficient level. ${ }^{13}$

Can this resource allocation problem be solved to ensure the optimal outcome? One theoretical answer is the Lindahl model, where the firm and the worker are assumed to pay personalized prices that reflect their individual marginal valuations. The supplier of $s$ receives payments from both parties, and supplies the optimal amount. At first sight, this seems a rather unrealistic suggestion. However, it turns out to be equivalent to a noncooperative situation where each side contributing chooses its contribution taking the other side's cost share as given. ${ }^{14}$ Again, this may seem an unlikely assumption for the case of a firm and a worker trying to agree on working conditions. However, it may have some relevance to the case of many workers trying to reach an agreement among themselves (see below), or of a union collectively representing workers in trying to reach

\footnotetext{
${ }^{12}$ Mathematically, if $s$ denotes the level of working conditions, $u$ the worker's utility, $F$ the firm's production function, $p$ the price of output, and $c(s)$ the cost of providing the working conditions at level s, the marginal benefits to the worker and firm are, respectively, $u_{s}, F_{s}>0$. The condition for optimality (maximizing the sum of benefits) is then $u_{s}+p F_{s}=c^{\prime}$. See Appendix 2 for a further discussion of the cost function, which may be generalized to depend on the size of the firm.

${ }^{13}$ In a voluntary contribution game, the firm and worker noncooperatively decide on contributions. Let the contributions be $s_{w}$ and $s_{f}$, measured in terms of the job characteristic itself, and the reduced form benefit functions be $v\left(s_{w}+s_{f}\right)$ and $\pi\left(s_{w}+s_{f}\right)$, where the other arguments are suppressed. Then the worker chooses $s_{w}$ to maximize $v\left(s_{w}+s_{f}\right)-c\left(s_{w}+s_{f}\right)$, taking the firm's contribution as given. The firm makes a similar choice. The Nash equilibrium of this game does not yield the optimal amount.

${ }^{14}$ This equivalence is shown in Cornes and Sandler (1986).
} 
agreement with a firm. The point of this discussion is to suggest that there could be mechanisms for overcoming free-rider problems that do not involve the direct imposition of labor standards by some external policy maker. Appropriate processes or institutions that allow for collective bargaining by workers may have some value in overcoming the public goods resource allocation problem, which is precisely a collective action problem. ${ }^{15}$ Thus labor standards that support rights of collective action by workers may have a justification in terms of promoting more efficient outcomes, as well as a direct justification from a rights-based perspective. Of course the latter justification is broader, since it presumably applies even when collective action worsens outcomes.

To round out our earlier analysis of the public goods problem, we may note that in the case of many workers the problem is essentially the same. The optimal level of working conditions is determined by the condition that the sum of the marginal benefits of all the workers and of the firm be equated to the marginal cost of improving the level of working conditions. ${ }^{16}$ There is a free-rider problem not only between the firm and workers, but also among all the workers. It is this latter problem that might be directly addressed by a union as an institution for collective action. The union may also provide a mechanism for workers to collectively negotiate a level of provision of working conditions with the firm, as we have discussed earlier. In fact, it seems that this has been one of the main roles of unions in practice, in addition to bargaining over wages and hours.

We close our discussion of working conditions as a public good by returning to the compensating differentials model of labor markets. If a firm competes simultaneously for many workers, and faces free entry that will push its profits down to zero, it will choose a wage for each worker and a common level of working conditions so that it maximizes the total utility of its workforce. It must do this to avoid being outbid for workers by a competing firm. In this case, competition also solves the public good problem with respect to working conditions, with the firm acting much as a club that

\footnotetext{
${ }^{15}$ Olson (1965) is the classic reference on this perspective, though he highlights also many of the practical difficulties and inefficiencies of collective action.

${ }^{16}$ The mathematical condition, modifying that in footnote 12 , is now $\Sigma_{j} u_{s}^{j}+p F_{s}=c^{\prime}$, where $j$ indexes different workers.
} 
maximizes the utility of its membership. This point is demonstrated more formally in Appendix 2. Even if firms are not constrained to zero profits by free entry, in this case of compensating differentials they will push workers down to their reservation utility levels in an efficient way, as they set wage-working conditions combinations to maximize their profits. This can raise concerns about equity, and workers' tradeoffs between wages and working conditions will be different at lower levels of utility, but there is no longer a straighforward problem of underprovision of working conditions as a public good. Allowing collective action by workers may still be supportable on distributional and rights grounds, but not on the basis of improving efficiency.

\subsection{Monopsony}

The model of compensating differentials allows for a kind of perfect wage discrimination by firms. This overcomes inefficiency problems that are sometimes associated with imperfect competition. Competition through free entry in the compensating differentials model redistributes from firms to workers, but does not affect efficiency. It is possible, however, that firms may have market power but not be able to discriminate among workers with different tradeoffs between consumption and work/leisure or to pay different wages for different hours worked. In such cases, we have the familiar inefficiency associated with market power, where the market wage does not properly reflect the value of the marginal product of workers.

In fact, market power leads to a wage that is below the value of the marginal product of labor. One can therefore also object to this outcome on grounds of inequity. Finally, the unequal position of the firm and the worker in the labor market might be considered to be unacceptable on the basis of procedural considerations. We will illustrate the market power outcome, and then discuss implications for labor standards policy. We have titled this subsection "monopsony", which is the case of a single buyer of labor, but the discussion also carries over to any firm with labor market power in the sense of a realization that the wage rate that it offers will affect the quantity of labor that is supplied to it. 
Figure 3: Monopsony in the Labor Market

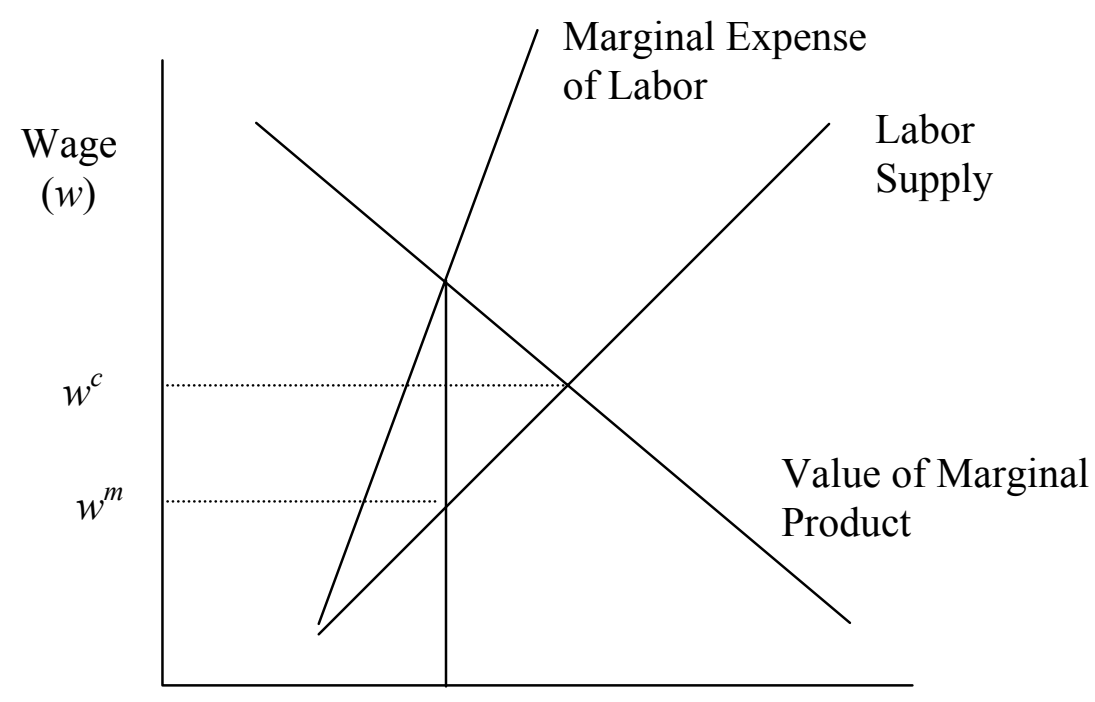

Hours worked $(h)$

In Figure 3, the firm faces an upward sloping supply curve of labor. If it seeks to hire more labor (either more hours by a worker or more workers), it realizes that the wage offered must rise. The assumption here is that all hours worked receive the same wage. Hence, in this case, the firm's marginal expense of labor is above the wage rate it pays, and the firm maximizes its profit by choosing the amount of labor that equates its marginal labor expense to the value of the marginal product of labor. This is shown by the intersection of those two curves, and the market wage in this case is $w^{m}$, which is the wage at which this amount of labor will be supplied. The inefficiency and the possibly unacceptable distributional aspects of this outcome are both reflected in the fact that the equilibrium wage (the opportunity cost of the marginal hour worked) is less than the value of the marginal product of that hour.

This analysis is presented mathematically in Appendix 3. Mathematical analysis allows one to consider the simultaneous choice of working conditions by the firm. The monopsonistic firm will, in choosing the level of working conditions to offer, take account of its own costs and benefits, but also the impact of changes in working 
conditions on the supply of labor. It turns out that one cannot say anything in general. The monopsonist may choose working conditions that are too high or too low.

In any case, with or without the issue of working conditions, one policy response to the inefficiency illustrated in Figure 3 is to impose a minimum wage. If appropriately chosen, the minimum wage can ensure the conditional optimality of the firm's choice of labor (so that the marginal value product equals the wage). In particular, this efficient minimum wage level is $w^{c}$ as shown in Figure 3. This is the level at which the value of the marginal product of labor and the opportunity cost of the last hour worked are equated. Of course this does not lead the firm to take account of the marginal benefit to workers in determining its choice of the level of working conditions. The inefficiency in that dimension is not caused by monopsony in the choice of labor input, so it requires a separate policy response. Furthermore, Dickens (1984) has shown that the effect on welfare of imposing a labor standard alone (without a minimum wage to correct the monopsony distortion) is also indeterminate. Our conclusion is the familiar one that multiple distortions require multiple policy instruments. Finally, another option is collective bargaining over working conditions and wages, the case of countervailing power highlighted by T.N. Srinivasan in his comments. Tore Ellingsen, in his comments, sketches a model of bilateral bargaining where some regulation of standards can help workers in the overall bargaining outcome. ${ }^{17}$

\subsection{Survival}

The typical competitive story does not consider survival constraints for workers. In the presence of a survival constraint, there might be a role for a minimum wage even in the case of competition, as suggested by Raynauld and Vidal (1998). The survival constraint leads to multiple equilibria, and the minimum wage can ensure that the "bad" equilibrium for poor workers is ruled out. Thus the policy justification is based on equity rather than efficiency grounds - in the case of monopsony, both equity and efficiency can be enhanced by an appropriately chosen minimum wage. 
Suppose that workers maximize their utility over income (which in turn is used for consumption) and work/leisure hours, where they take the competitive wage as given. Furthermore, they are subject to an additional constraint, namely that a worker's income must be at least some minimum level that permits survival. If this survival constraint does not bind the worker, (s)he will satisfy the usual marginal conditions, which imply a supply curve that will typically be upward sloping, that is, a lower wage decreases the number of working hours (neglecting the possibility of a backward-bending supply at high incomes). On the other hand, if the survival constraint binds, then the usual marginal conditions are overridden, and the worker simply chooses enough working hours to survive: in this case, a lower wage increases the number of working hours. ${ }^{18}$

\section{Figure 4: Multiple Competitive Equilibria with Survival Constraint}

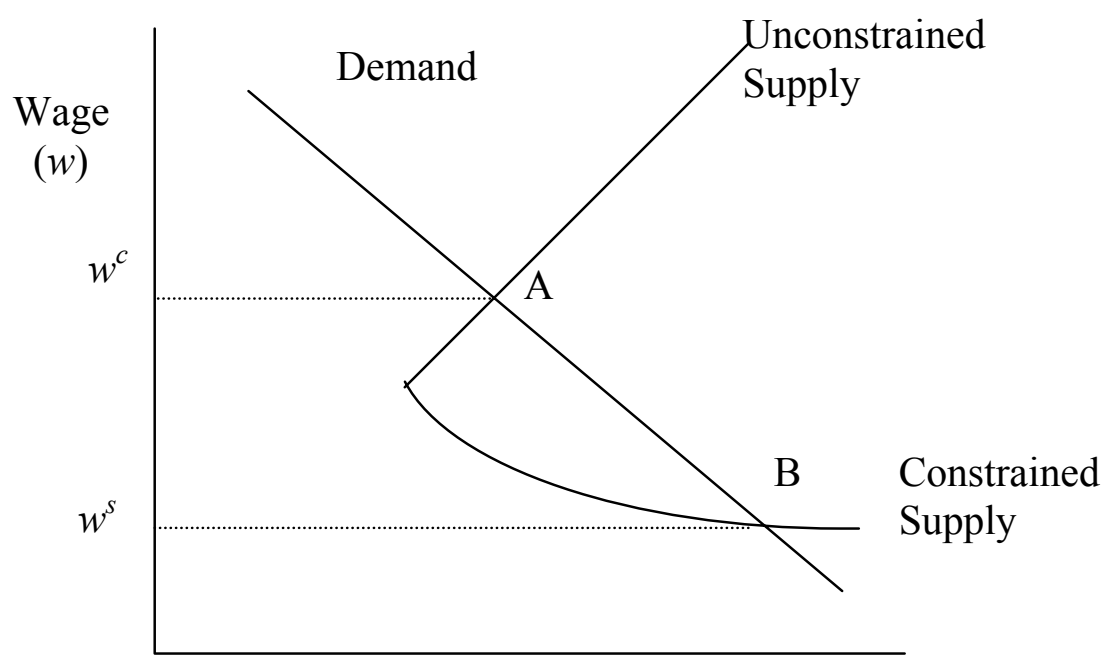

Hours worked $(h)$

\footnotetext{
${ }^{17}$ Ellingsen also suggested Datta and Chowdhury (1998) and Fairris (1995) as additional references.

${ }^{18}$ Formally, the worker maximizes $u(x, l)$ subject to $x=w h, h=T-l$, and $x \geq x_{0}$, where $x$ is both consumption and income, $l$ is leisure, $h$ is hours worked, $w$ is the wage rate, $T$ is the endowment of time, and $x_{0}$ is the minimum consumption level for survival. The standard equilibrium is given by the interior first order condition, $u_{x} / u_{l}=1 / w$, which can be solved for the supply function $h^{S}(w)$. However, this may involve violating the survival constraint. If that constraint binds, the supply curve is given by $h^{S}=x_{0} / w$.
} 
The two components of the supply curve are shown in Figure 4, along with a competitive demand curve, which slopes downward. The demand curve is based on the standard assumption that firms demand the amount of labor at which the value of the marginal product equals the wage, taking the wage as given by the market. The supply and demand curves intersect twice, so there are two equilibria. At point A, the worker earns above subsistence income with a wage of $w^{c}$, but at point $\mathrm{B}$ he is held to a lower, subsistence wage, $w^{s}$. If firms can make wage offers as in the compensating differential story outlined earlier, then the subsistence equilibrium cannot survive, since there are wage-hours contract offers that will generate a profit and make workers better off. However, since the standard competitive story has wage-taking firms, such a situation would allow the worse equilibrium to persist. Note that if there is competition in the product market, firms will earn zero long run profits in either equilibrium, and consumers are the ones who benefit from the workers" "bad" outcome.

In the above framework, a minimum wage above the subsistence wage will rule out the subsistence-wage case, and lead to the higher-wage equilibrium, making the poor workers better off. This is the essence of the Raynauld-Vidal argument. This kind of argument seems to formalize the thinking of many who are concerned about "sweatshop" wages being forced on workers through their necessity. However, this model may not capture the real concern, for the following reason. The subsistence-wage equilibrium marked by point B in Figure 4 is not stable. A small perturbation that pushes the wage above $w^{s}$ creates excess demand rather than excess supply, and in this case the wage should rise all the way to $w^{c}$, the usual competitive wage, which would be the only equilibrium that persists. Note that the instability of the low-wage equilibrium is behind the fact that competitive wage contract offers by firms will rule out that equilibrium, as discussed in the previous paragraph.

The survival issue can be considered in a different light, however. In this alternative, the survival equilibrium is the only competitive equilibrium. In this case, a minimum wage is not the appropriate policy, because it would endanger workers' survival. This is illustrated in Figure 5: point B is the only intersection of the supply and 
demand curves, and is the unique, stable competitive equilibrium. ${ }^{19}$ In the absence of the subsistence constraint, the equilibrium would have been at $\mathrm{C}$, with a higher wage and fewer hours worked. In the given situation, however, a minimum wage above $w^{s}$ simply creates excess supply, and reduces workers' ability to survive. In this circumstance, the only way to improve the lot of workers may be to increase their productivity, shifting the labor demand curve up, and getting them above subsistence income levels. In Figure 5, this is illustrated by the starred demand curve, with a new equilibrium at A. The contrast between Figures 4 and 5, and their policy implications, illustrates one of the differences in perspectives that lead to debates about the appropriate nature and role of labor standards. In the case of Figure 5, the correct policy intervention if one wishes to improve the lot of poor workers is one that raises their productivity. We return to such approaches in the penultimate section of this paper.

Figure 5: Unique Competitive Equilibrium at Subsistence

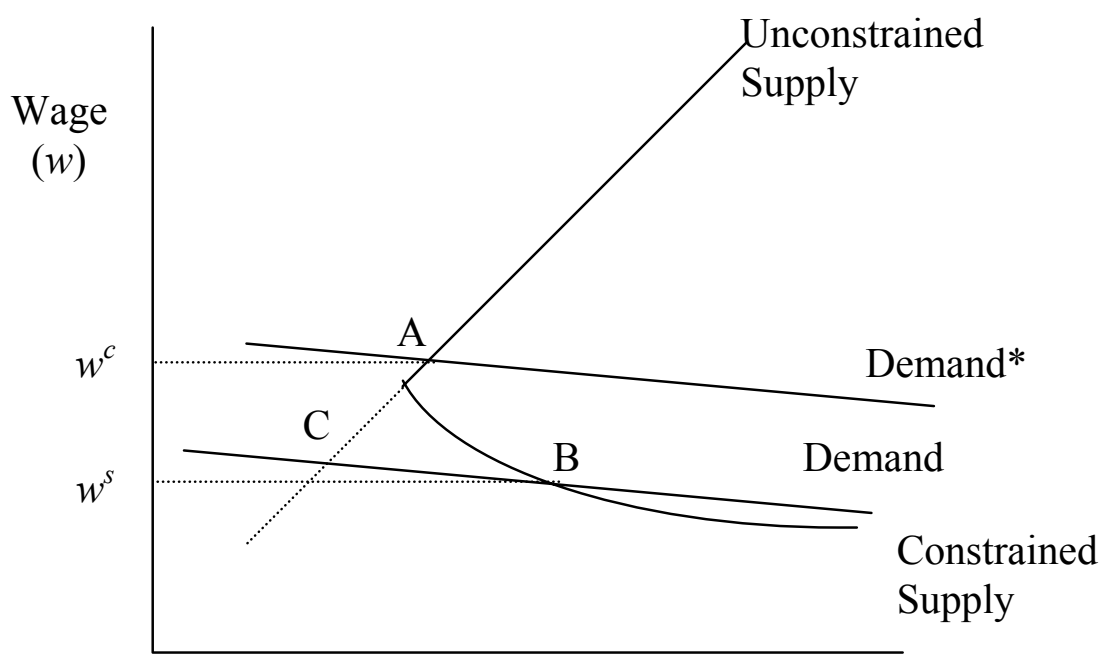

Hours worked $(h)$

\footnotetext{
${ }^{19}$ Note that the demand curve may or may not intersect the constrained part of the supply curve again, depending on its continuation. Whether it does or not is inessential to the analysis. In this case, competitive wage offers by firms also do not affect the outcome.
} 
In the consideration of survival constraints up to this point, we have not allowed any role for working conditions, beyond the wage and number of hours worked. However, working conditions may also be affected by the existence of survival constraints. This can happen in several ways, depending on what one assumes about the markets for labor and for working conditions (standards). Let us assume first that there is no productivity benefit from improving working conditions but that workers are better off with better conditions. In the absence of a market for working conditions, firms will choose the minimum feasible level of those conditions, whether there is a survival constraint or not. If there is a competitive market for working conditions as a private good (e.g., workers can buy safety glasses), then we get optimality in the absence of a survival constraint. Adding the survival constraint does not change the tradeoff at the margin between more leisure and better working conditions, but since the worker is working longer hours to survive, her marginal utility of leisure is higher, implying that adding the survival constraint raises the marginal utility of working conditions in equilibrium, so these must be at a lower level in this equilibrium. In the extreme case, the worker's demand for working conditions could be reduced to zero: intuitively, this just reflects the poverty of the worker. Imposing standards that mandate higher than equilibrium working conditions (with costs borne by the firm) in this case simply shifts the firm's demand downward, requiring the worker to work longer hours at lower pay to survive.

Finally, consider the case where firms can make offers combining wages and working conditions, as in models of compensating differentials. Recall that competing firms make zero profits with free entry, and workers' utility is maximized subject to this zero profit constraint. The zero profit constraint determines a locus of wage-workingconditions combinations that are feasible, irrespective of whether a survival constraint is present or not. A higher wage paid must be compensated for by worse working conditions in order to keep profit at zero. Adding a survival constraint changes workers' tradeoffs between wages and working conditions, in favor of the former, so that a given worker would prefer a combination with a higher wage and lower working conditions. Again, the survival constraint worsens working conditions, but there is no simple remedy: 
mandating higher standards will simply make workers worse off as firms adjust by reducing wages. ${ }^{20}$

\subsection{Information}

The smooth working of all markets can be derailed by asymmetries of information (see Stiglitz, 2000, for an overview and references). Under conditions of imperfect or incomplete information, market outcomes may be inefficient relative to a situation of perfect or complete information. Less obviously, market outcomes may sometimes not even be efficient given the constraints imposed by the available information. Depending on the situation, potential remedies may be policies to directly influence outcomes, or policies that are designed to do so indirectly, by improving the collection and exchange of information. Since information has public good characteristics, some of the issues discussed in Section 3.3 will arise in the context of the production and consumption of information, but we will not repeat the earlier discussion. One can also take a rightsbased approach, and argue that market participants are entitled to certain kinds of information, independently of the impact on market outcomes. Here, worker outcomes in the labor market are wages, hours and working conditions in general. For employers, outcomes are the productivity or output of their employees. To the extent that employers are relatively privileged and that we care about equity, the focus is typically on the outcomes and rights of workers.

An area where workers and employers may commonly lack full information is that of safety and risks. These may include the possibility of accidents, negative health consequences from chemicals, and so on. One side effect of the industrial revolution has been the vastly greater complexity of the workplace, and the multiplication of potential risks. Even traditional occupations may have unknown long-term consequences, such as injuries from repetitive motions. Given this complexity, it is not surprising that both

\footnotetext{
${ }^{20}$ These negative conclusions on the efficacy of policy can be tempered if firms make positive profits. Adding a survival constraint may allow firms to offer lower working conditions as well as lower wages. Imposing standards relating to working conditions may then benefit workers even in the absence of a minimum wage.
} 
employers and workers may be uninformed, or poorly informed about safety, risks and so on. Public good problems can hinder the efficient private collection of the relevant information. Even if information is available, participants may not have incentives to disseminate it optimally, or they may not be able to credibly exchange information. For example, workplace risks could conceivably be handled by insurance, but this can be made difficult to achieve efficiently, or at all, by problems of moral hazard and adverse selection.

In the compensating differentials model discussed in Sections 3.2 and 3.3, workers are fully informed about working conditions, including on-the-job risks. However, the empirical evidence appears to be that workers commonly underestimate job risks. This can potentially create inefficiencies in the labor market. Oi (1973) shows that the existence of workers who underestimate job risks is not by itself sufficient to cause a misallocation of workers to dangerous jobs - the risk assessments of marginal workers is what matter. Under plausible conditions, however, the market equilibrium does involve suboptimal levels of working conditions. There are numerous models with variations on this theme, surveyed in Dickens (1984), which support the basic theme that informational gaps may or may not cause problems in the efficiency of resource allocation, in particular, exposing workers to more risk than would be socially optimal in a world of full information, according to any standard welfarist objective.

The rationale for government intervention in cases of nonoptimality must be based on the assumption that the government is better informed or that it can become so at lower cost than individuals or firms. For many kinds of health and safety information, this is a very plausible and realistic assumption. The natural policy then might be simply to inform workers about the true risks of jobs. However, if this does not succeed in informing workers perfectly (because the government's information transmission is noisy, or because workers do not interpret it perfectly) Dickens (1984) shows that workers may be worse off with such partial improvements in information. In such cases, government mandated standards (if properly enforced, of course) might be superior. 
Note that the presence of imperfect information on the part of workers, and possibly also firms, means that competition where firms offer compensating differentials is not enough to make the market equilibrium efficient. For example, suppose that worker preferences over wages and working conditions are heterogeneous, but that firms cannot distinguish workers according to these preferences. With complete information, firms would be able to vary wages across workers, even if, by assumption, they must offer the same working conditions to all workers. Lacking information on preferences, this is no longer possible, because a worker will always claim the highest wage offered, and therefore a firm must pay all its workers the same wage. Even if firms can screen workers by offering them nonlinear wage schedules to induce self-selection, the outcome is not necessarily efficient, and competition can even destroy the possibility of a market equilibrium. More realistically, firms are unlikely to be able to engage in such complex strategies.

Brown, Deardorff and Stern (BDS, 1996) consider a model, in which there is a distribution of workers and firms in two different industries, but firms cannot directly identify worker preferences. The job characteristic is treated as job safety, but it could be any aspect of working conditions that affects workers' welfare. In the model, there are more workers than firms, and levels of safety will differ across firms in the market equilibrium. A marginal worker in a firm will be indifferent between that firm and the alternative firm with the closest safety level. BDS show that if the distribution of worker preferences is more concentrated in the middle (as would be realistic), firms that are safer than average will actually be less safe than would be optimal based on the preferences of the workers that they employ, while firms that are less safe than average are actually safer than would be optimal for the workers they employ. Thus firms' offered safety levels are also skewed toward the middle. ${ }^{21}$

While the result obtained by BDS is theoretically interesting, it does not seem to be very significant from the perspective of labor standards policy, because the least safe 
firms are "too safe". Empirically, we observe firms with different levels of working conditions, and it is unlikely that we would recommend that the safer firms tighten up their standards, while the less safe ones become more lax. Clearly, when we observe variation in working conditions, the situation is likely to be driven by other factors than differing worker preferences, and attempting to apply the BDS model would be misleading.

\subsection{Free Contracting, Rights and Welfare}

In this subsection, we turn more explicitly to questions that revolve around rights. In Section 2, we noted the importance of rights-based perspectives in practical formulations of labor standards, and we examined the manner in which such perspectives interact with welfarist approaches that focus on consequences or outcomes. Here we examine two models that illustrate these interactions in more specific situations. One right that is often supported is what Basu (1999) has termed the "principle of free contracting", which asserts that an individual should have the right to voluntarily enter into any contract, since voluntariness implies a welfare improvement. ${ }^{22}$ This seems like an eminently reasonable right, supporting free choice, which does not appear to conflict with welfarist objectives. However, the models described below illustrate some possible limitations on the principle of free contracting, and with the argument that no voluntary contracts should be prohibited. In his comments, Tore Ellingsen provides two further possible cases for restricting contracting. In one, private information about productivity

\footnotetext{
${ }^{21}$ A technical point is in order here. BDS suggest that Pareto optimality implies that the average marginal rate of substitution between wages and safety in each firm is equal to the price of safety, which is defined as the cost of providing a unit of safety. However, if the latter is the actual marginal cost, the condition for Pareto optimality is that this be equal to the sum of the workers' marginal rates of substitution. Implicitly, therefore, the price of safety in BDS must be the marginal cost divided by the number of workers.

${ }^{22}$ More precisely, as stated by Basu (1999), "Economists usually take the line that a voluntary contract between two agents that does not involve negative externalities on uninvolved outsiders ought not to be banned." Here Basu means direct and not pecuniary externalities. As will be seen in the subsequent discussion of Genicot's analysis, there may be pecuniary externalities when the availability of one type of contract drives out another type. Srinivasan suggests in his comments that this endogeneity of contracts being offered calls into question the applicability of the free contracting principle - however, this critique is less relevant for Basu's model.
} 
leads to an inefficient "rat race" because of informational externalities. ${ }^{23}$ Second, restrictions on giving up workplace and related civic rights may be efficient because they prevent free riding in the provision of a public good, a problem that was analyzed in Section 3.3.

Bonded Labor Once bonded, a worker is unfree, but the act of choosing to be bonded can be voluntary. Bonded labor can include peonage, debt slavery attached labor and even contract labor can be included in the term "bonded labor". The argument in Genicot (2000) is based on showing that the existence of bonded labor can hinder the development of welfare enhancing credit opportunities for laborers. In her framework, the set of opportunities for the worker is so limited that these contracts may represent their best option. One can, of course, make a case for banning bonded labor on rightsbased grounds alone, with the principle of free contracting subordinated to the right to remain "free to choose." Alternatively, one may argue that the workers have limited rationality or incomplete information, possibly combined with moral hazard on the part of employers. Furthermore, nonlinear discounting and endogenous preferences have been used to explain the suboptimality of bonded labor. Genicot provides a plausible alternative to some of these narrower, more technical justifications.

Genicot shows that a ban on bonded labor can enhance the welfare of the laborers affected by the ban. The crux of the argument is that the set of choices available to the individual facing the bonded labor option is endogenous. In other words, banning bonded labor improves the overall set of options that the worker faces. The way this works in her model is as follows. Formal credit institutions may refuse credit to the poor in the presence of bonded labor, because the presence of the bonded-labor option raises the risk that the borrower will default and switch to that alternative. As a result, the worker is not offered formal credit, and instead must choose the bonded labor contract. In this case, the landlord has greater enforcement power than the formal credit institution. To the extent that the existence of the formal credit option influences the landlord's choice, he is making a strategic decision that results in bondage, i.e., he is choosing a

\footnotetext{
${ }^{23}$ Thus this model is related to those discussed in the previous sub section. The general analysis of Aghion and Hermalin (1990) has its antecedents in Akerlof's (1976) seminal article.
} 
contract that destroys the option of a formal credit contract being offered. Side payments from the landlord to the worker may, in some cases, have the same effect as commitment in destroying the formal credit equilibrium.

The above argument in favor of banning bonded labor is ultimately based on grounds of equity and not of efficiency. Banning bonded labor makes the worker better off at the expense of the landlord. It is not a Pareto improvement, which would mean that one individual is made better off without reducing the welfare of any other individual. Philosophically, the issue may be deeper. Basu (1999) points out that the distinction between 'coercion' and 'free choice' entails a prior opinion on what constitutes basic human rights. The question in this case is whether the worker's right to borrow from a formal credit institution is such a basic right. However, if this right is conditional on the level of income of the worker, then it seems that it is not really basic. The basic right must be something else, such as that of making choices from a set that allows the chooser to preserve a level of autonomy and dignity, or to achieve a basic standard of living. This illustrates again the broader issue of what rights we should care about, taken up in the paper's penultimate section.

Working Conditions Basu (1999) also considers problems with the principle of free contracting, in a manner somewhat different than Genicot. He asks, "Is there a case for banning violence and sexual harassment when these occur as a consequence of voluntary contracting?" Here, violence and harassment can be taken as two important examples of a particular category of working conditions. Basu postulates that an entrepreneur advertises for workers, openly saying he will pay a wage above the market wage rate, but this goes with reserving the right to harass his workers (other working condition may be substituted for harassment). In this case, workers who are averse to harassment will be worse off if harassment is allowed.

The supporting argument for the above assertion is as follows. Suppose there are two types of workers, those with no aversion to harassment and those with an infinite aversion. Each type has an upward sloping supply, as a function of the wage rate. Employers and workers are competitive wage takers. If the employer receives a constant 
additional benefit per worker that he can harass, this will be the difference in wages in two types of contracts that can be signed (harassment and no-harassment). However, at the margin, the wage is determined by the marginal product to the employer of those who are averse to harassment. Note that freedom from harassment is different from overall safety or sanitation, as discussed earlier, in that it is not a pure public good, but can be provided at a cost to a subset of workers. Banning harassment contracts reduces the wage of those who are willing to endure harassment (since their value to the employer is lower), and therefore their equilibrium supply. However, it increases the wage of those who are averse to harassment. Thus the latter are worse off if harassment contracts are allowed: this is a standard pecuniary externality.

As in the case of Genicot's analysis, banning harassment contracts does not lead to a Pareto improvement. Employers and workers who are not averse to harassment are worse off as a result. Basu notes that the argument hinges on going "beyond economics" to identify preferences that are "fundamental", in the sense that "no one should have to pay a penalty for having such a preference." Sexual harassment seems to fit this criterion (for most societies). Minimal levels of safety at work would also seem to be appropriate. However, there are two points to note. First, there is a very explicit value judgment that must be made here. Second, following the first point, there can be legitimate disagreement on such values, in particular, where one draws the line. Basu argues that the same issues arise in the case of child labor, where households that are averse to sending their children to work can be penalized in the market if child labor is allowed. We take up the issue of where and how one draws the line in such cases in Section 5.

\section{Labor Standards in the Global Economy}

In Section 3, we have provided an overview of possible reasons for labor standards, either as regulations that directly set standards for outcomes (such as wages or working conditions), or as requirements on labor market processes (such as collective action or individual contracting rights). These issues with respect to the working of labor markets arise in a closed economy, and are not necessarily driven by concerns that 
transcend national boundaries. We now turn to some aspects of the links between international economic flows and labor standards. Some of the issues that arise with respect to the appropriateness and nature of these links are taken up in Section 5.

In this section, the general theme is the impact of international trade on labor standards that are determined endogenously. We first examine whether international trade in goods has a causal link to inefficient labor standards. We briefly also discuss the link between trade negotiations and labor standards, as analyzed by Bagwell and Staiger (2001). However, we do not go in much detail into general issues of enforcement of labor standards, and whether trade sanctions are an appropriate tool for enforcing international labor standards. The second issue we address is whether trade hurts the poor (low-skilled) through its impact on labor standards. Thus the focus here is on distributional concerns rather than problems of inefficiency in resource allocation. Finally, we consider the choice of labor standards by competing countries, in which capital flows as well as international trade in goods are often given a role. There can be efficiency issues as well as distributional concerns in such "races to the bottom," where the term describes the lowering of labor standards by one country in strategic competition with other nations.

\subsection{International Trade and Labor Standards}

Srinivasan (1994, 1996; see also Bhagwati and Srinivasan, 1996) provides a lucid benchmark analysis of the possible links between international standards and international trade. He uses a model of a small open economy with perfectly competitive markets. He shows that labor standards will be chosen efficiently - none of the problems discussed in Section 3 are present. This result, not surprisingly, does not depend on whether international trade occurs or not. In particular, he considers an economy with two regular traded goods and a third nontraded good, which is the economy-wide level of the labor standard. As is standard in international trade models, there are given endowments of the inputs, labor and capital, and the feasible frontier is defined by a production possibility frontier that relates the outputs of the three goods, given the aggregate input endowments. Aggregate social welfare is captured in a Samuelson social 
utility function, which depends on the consumption of the two traded goods and the level of the labor standard. ${ }^{24}$ Thus the labor standard enters social utility positively, while maintaining a higher standard entails a resource cost.

In this framework, the small open economy faces a given relative price of the two traded goods. With perfectly competitive markets, the economy's choices of consumption, production and the labor standard are equivalent to those determined by maximizing social utility subject to the production constraint, nonnegativity constraints, and the trade balance requirement. ${ }^{25}$ It is a straightforward and standard result that the outcome here is Pareto optimal, including the choice of the labor standard. In other words, no one can be made better off without making someone else worse off. This is a natural extension of the first welfare theorem of economics to incorporate labor standards. Srinivasan also points out that this Pareto optimal level will diverge across countries whenever preferences and resource endowments are heterogeneous.

Note that this conclusion tells us nothing about distributional issues, since the model is too aggregate to address such concerns. Here the implementation of standards is uniform within a country, and maximizes some unambiguous measure of aggregate social welfare. We will turn to distributional concerns in the next subsection, in examining the issue of winners and losers from trade. Public good problems in implementing standards - which we addressed in Section 3.3 - are also put aside in this formulation. Nor is there any consideration of processes or rights independently of welfare outcomes. Finally, political economy issues are also treated separately by Srinivasan (see Section 5 of this paper). Nevertheless, the results provide a useful benchmark for judging international labor standards, both in terms of rationale and precise implementation. Furthermore, one can argue that any such problems are ones of domestic implementation, and can or should be handled by domestic policies.

\footnotetext{
${ }^{24}$ The formal notation is as follows. $\mathrm{Q}_{\mathrm{i}}$ and $\mathrm{C}_{\mathrm{i}}(\mathrm{i}=1,2)$ are the production and consumption, respectively, of the two goods. $\mathrm{S}$ is the level of the labor standard. $\mathrm{U}\left(\mathrm{C}_{1}, \mathrm{C}_{2}, \mathrm{~S}\right)$ is the Samuelson social utility function, and $\mathrm{Q}_{1}=\mathrm{F}\left(\mathrm{Q}_{2}, \mathrm{~S} ; \mathrm{L}^{0}, \mathrm{~K}^{0}\right)$ is the production possibility frontier, given the endowments $\mathrm{L}^{0}, \mathrm{~K}^{0}$ of labor and capital.

${ }^{25}$ Let the world relative price for good 2 in terms of good $1 \mathrm{be}$. Using the notation of the previous footnote, the equation for the trade balance requirement is $\mathrm{C}_{1}+\mathrm{pC}_{2}=\mathrm{Q}_{1}+\mathrm{pQ}_{2}$.
} 
Srinivasan goes on to show that, even without balanced trade in each country, any world Pareto optimum of production, consumption and standards (possibly different for each country) can be supported as a competitive equilibrium, i.e., as a free trade equilibrium. Unbalanced trade means that lump sum transfers may be required to support a particular world Pareto optimum. Srinivasan's contribution here is to show that the standard second welfare theorem of economics extends easily to include labor standards. Again, labor standards will in general be heterogeneous across countries.

Srinivasan also discusses the possibility that one can find a world Pareto optimum even when a minimum global labor standard is required. On the other hand, if the minimum standard is too high, a full Pareto optimum will be ruled out, and a restricted Pareto optimum, with a binding minimum standards constraint for some countries, will instead apply. In this case, there is a wedge between the marginal rate of substitution (MRS) between either consumption good and the standard on the one hand, and the marginal rate of transformation (MRT) in production between the same consumption good and the standard. Srinivasan points out domestic taxes and subsidies in countries where the minimum standard is binding will implement the Pareto optimum. There is no role for trade restrictions or other international policies.

Why should a minimum global labor standard be imposed at all, if it reduces welfare? Here one can introduce concerns about rights, taking the approach that the standard represents a consensus that countries agree to impose on themselves collectively, because it represents a concern about more fundamental rights that transcend immediate welfarist concerns. This is not too different from constitutional restraints within countries, which tie the hands of future governments even if they are acting in a "benevolent" manner. In the current example, there is an added international dimension. Srinivasan plausibly equates the minimum global standard in the abstract model with ILO conventions, and, together with his conclusions on the role of lump-sum international transfers and domestic taxes and subsidies, is led to state, "Indeed one could view the international assistance and domestic compliance measures associated with implementing ILO Conventions as precisely the right approach. There is no need for any social clause." (emphasis added) 
International consumption externalities are also considered in Srinivasan's framework. $^{26}$ With such externalities, the MRT in production between either consumption good and the standard in a country - call it $\mathrm{A}$ - is equated to a weighted sum of the MRS between that consumption good and country A's standard, where the sum is over all countries which care about A's standard. Again, the appropriate policy response to this externality is domestic taxes and subsidies that directly address the externality.

Srinivasan's use of Pigovian welfare economics to analyze issues of international labor standards is a useful benchmark. He extends it to a discussion of other market failures, such as capital market imperfections. Again, he argues that the best policy is to correct the externality at its source. Srinivasan notes that informational requirements may make such policy interventions difficult or impossible. We consider separately a further possible implication of this observation, that second best policies may involve targeting in ways that include a focus on labor standards. The targeting issue also is relevant to income distribution considerations, where efficient direct income transfers may not be feasible because of informational constraints. This may apply to international as well as domestic transfers. We touch on these issues in Section 6.

Brown, Deardorff and Stern (BDS, 1996) examine many of the same issues as Srinivasan (1996). They also show that in a small open economy, correcting a labor market externality through a domestic standard improves domestic welfare, using a utilitarian criterion. In an importing sector, imports go up as a result of the standard. A common international standard has potentially different effects. While the loss to domestic producers is partly made up by the increase in the world price resulting from the global reduction in supply, domestic consumers are hurt, and the net gain may now be negative. Net exporters, on the other hand, definitely benefit from common standards. Common standards create terms-of-trade effects, and these may by themselves provide a motivation for imposing labor standards in a large country. This examination of terms-oftrade effects distinguishes the BDS analysis from that of Srinivasan.

\footnotetext{
${ }^{26}$ We will consider these in more detail in Section 5, along with a discussion of product labeling.
} 
In the case where economies are specialized, the BDS analysis implies that large countries acting noncooperatively will set standards too high, relative to the world optimum, since each tries to influence the terms of trade in its favor by raising its standard. Cooperation, or harmonization, will lead to lower standards. In a general equilibrium Heckscher-Ohlin model, the effect of a labor standard depend on how the factor requirements of the standard compare to the factor requirements of world production. For example, a labor standard that is more labor intensive than the world labor-capital ratio will raise the world relative price of the labor-intensive traded good, regardless of who exports the good. This means a terms-of-trade effect that benefits the labor-intensive country. Alternatively, BDS also consider standards that are industryspecific. The results in that case are quite similar.

Therefore, in this framework, to the extent that most forms of labor standards are primarily or wholly labor using, they will increase the world relative prices of laborintensive goods, improving the terms of trade of countries with labor-intensive exports. This analysis would suggest that, purely from the terms-of-trade perspective, less developed countries (developing countries) would want higher labor standards, and developed countries would not. Therefore the analysis seems to be at odds with the current debates on international labor standards. Of course this conclusion neglects different interests within countries. For example, owners of capital may disproportionately influence policy.

Bagwell and Staiger (2001; see also Staiger, 2001) also consider the links between labor standards and international trade. As in the BDS analysis, they allow for terms-of-trade effects. Unlike BDS, they assume that countries can choose optimal tariffs as well as their national standards. Standards are assumed to matter directly only at the domestic level in each country. Thus cross-border externalities, such as when consumers in one country care about the production methods used in a different country, are ruled out: we discuss such possibilities in Section 5. The domestic standards can be policies that are applied to production (specifying working conditions, for example) or to consumption (restricting consumption of products made using some kinds of processes). 
The Bagwell-Staiger analysis works with reduced-form welfare functions for national governments. National welfare as perceived by a government depends on local prices, world prices, and domestic standards. Since the wedge between local and world prices is created by tariffs, welfare also depends on tariff levels. Each government is able to choose its domestic standards and tariffs. While this reduced form approach is able to accommodate many different assumptions about domestic political economy, it may obscure some features of the model. In particular, Bagwell and Staiger focus throughout their analysis on the case where an increase in the national standard would worsen the terms of trade for every country. This is at odds, therefore, with the BDS analysis, in which the direction of impact of a standard on the terms of trade depends on the relative factor intensity of the export good.

The Bagwell-Staiger model also allows efficient policy choices, as measured by any weighted sum of all countries' welfare functions, to include positive tariff levels. Optimal domestic standards are also specified in the efficient outcome. On the other hand, if each government chooses it tariffs and standards independently, the resulting noncooperative Nash equilibrium involves inefficient levels of tariffs and standards. In this equilibrium, trade volumes are inefficiently low. The source of this inefficiency, as one might expect, is the desire of each government to affect the terms of trade in its favor. However, since national standards can indirectly influence the terms of trade, international agreements that only negotiate improved cross-border market access through lower tariffs will distort national standards choices. This makes a theoretical case for tying international negotiations on domestic standards to international trade liberalization.

There are, of course practical difficulties with the connection of domestic issues to international trade, as Bagwell and Staiger acknowledge and discuss. These include questions of where to draw the line in terms of what is included in trade negotiations. They also point out the difference in their analysis from arguments for a WTO "social clause," which proposes linking access to one's markets to the choice of standards by a trading partner, or the meeting of some minimum international standards by all trading partners. Instead, Bagwell and Staiger's approach emphasizes the need to formulate 
negotiating procedures in a way that will allow governments to raise their own domestic standards from inefficiently low levels. We discuss practical issues and policies in the subsection, after the next, on "races to the bottom", as well as in Section $5 .^{27}$

\subsection{Trade, Labor Standards and Skills}

BDS provide some consideration of the distributional impacts of international trade, and the consequences for labor standards within countries. Casella (1996) provides a general equilibrium analysis of labor standards and trade that specializes some of the assumptions as compared to BDS and Srinivasan. This allows a closer consideration of income distribution effects. In Casella's model the two factors are high-skill and lowskill labor, and the two consumption goods each requires labor of only one type: the outputs can be interpreted as high-tech and low-tech goods. As is standard, trade reduces the relative wage of the factor that is relatively scarce in autarky. Trade leads to a rise in the real income for low-skill labor in the country that has a relative abundance of lowskill labor, what we can treat as the developing country. Similarly, it leads to a rise in the real income of high-skill labor in the other, developed country.

Labor standards are modeled as an economy-wide public good, financed through labor taxes. If the technology for producing the public good is such that the relative demand for the two private consumption goods is unaffected, then relative prices are unchanged, and the level of the standard in one country has no effect on the other country. All workers prefer to be taxed proportionally to their income, with the constant of proportionality being the same. This means that higher income workers desire higher standards. If there are fewer high-skill than low-skill workers in each country, then highskill workers in each country will prefer higher standards than will low-skill workers. This result is quite intuitive, since it is driven by income effects alone. Furthermore, since trade can make everyone better off if there are suitable domestic transfers, those transfers will also lead to higher standards with free trade than with autarky. On the other

\footnotetext{
${ }^{27}$ Further references to the issue of international labor standards and trade may be found in Brown (2000a, b).
} 
hand, if there are no such transfers, changes in the demand for standards by any group will depend precisely on how their real income is affected by opening up to trade.

Note that in this model, since standards are an economy-wide public good, there is no possibility of a differential imposition of standards. If, on the other hand, standards can be imposed at differing levels across industries, then different groups' ranking of them will differ even more. For example, a standard implemented only in the low-skill sector will not be supported by workers in the high-skill sector (in terms of their willingness to be taxed), even though the latter would prefer a higher level of an economy-wide standard. However, if there were a positive externality, so that workers in the high-skill sector cared about the working conditions or other labor standards for those in the low-skill sector, then this conclusion would change. We examine such externalities in Section 5.

\subsection{Races to the Bottom}

The idea of a race to the bottom is quite pervasive in discussions of international labor standards. The broad idea in all of these discussions is that international competition will drive down labor standards in all countries, to levels that are too low, in terms of the allocational efficiency of outcomes, their distributional impacts, on the basis of criteria that emphasize rights and procedures, or some subset of these concerns. It turns out that there are many different possible formalizations of the race-to-the-bottom idea, and in this subsection we trace out some of these differences, and their implications for rationales for labor standards.

Much of the literature on the race to the bottom is situated in the area of local public economics. Since capital has always been relatively quite mobile within national boundaries, the concern has been that local or other subnational governments would compete for mobile capital by lowering local labor or environmental standards to attract firms to the benefit of local economies. The extension of this argument to the case of countries competing for internationally mobile capital is immediate. 
Local public economics also provides a counter-argument to the idea of a race to the bottom. Tiebout (1956) formulated a model in which individuals could move freely between jurisdictions, effectively "voting with their feet". In such a case, local government competition for residents can lead to efficient outcomes, as long as the local governments maximize land values, and have sufficient tax instruments at their disposal. While labor is certainly not freely mobile across countries, the Tiebout insight can be applied to mobile capital. The implication is that inefficiency and a race to the bottom are the result of some restriction on the tax instruments available to competing governments.

Relevant models of local government competition include those of Zodrow and Mieszkowski (1986), Oates and Schwab (1988), Bucovetsky and Wilson (1991), and Revesz (1992). Wilson (1996) re-examines and extends this set of models to clarify when races to the bottom could conceivably occur. As noted, the starting point of many of these models is a Tiebout-type framework in which jurisdictions compete for mobile capital. A race to the bottom occurs in such models when standards for some aspect of firm operations (pertaining to working conditions, environmental effects, and so on) are set inefficiently low. In general, with perfect competition and a complete set of taxsubsidy instruments, this inefficiency cannot occur. Therefore Wilson examines a range of possible limitations on the policies of jurisdictional governments.

One possibility is that mobile capital is taxed, because more efficient tax instruments are not available, and this, in turn, leads to standards that are more lax than is optimal, as a way of attracting capital. This result can occur even in the absence of capital taxation. If a jurisdiction's provision of a public good (even when financed through wage taxes) increases the supply of capital to other jurisdictions, then this externality implies that the public good (which may be related to working conditions, human rights, etc.) is underprovided relative to the optimum.

Alternatively, Wilson considers some different possibilities with respect to imperfect competition, which might be expected to lead to nonoptimal outcomes. If jurisdictions are large enough demanders of capital that they influence the equilibrium after-tax rate of return on capital, net importers of capital have an incentive to tax it to 
improve their terms of trade. However, the optimal tax on capital does not cause a deviation from choosing optimal labor standards. One has to appeal to inefficiencies in the collection of capital taxes to generate a possible race to the bottom.

Several other models of imperfect competition also do not support races to the bottom. The complications arise because imperfect competition among firms itself creates inefficiencies, and taxation has impacts on these inefficiencies, as well as on the possible levels of working conditions or labor rights. A further complication occurs when competing jurisdictions are assumed to be exporting to a different jurisdiction, or seek to attract firms owned outside their any of their jurisdictions. Whether the welfare of the 'non-residents' is counted can affect the welfare evaluation of the outcome. The conclusion from the local public economics literature appears to be that the possibility of an international race to the bottom, taken to mean inefficiently low domestic labor standards, is highly dependent on the particular set of assumptions made about competition and policy instruments.

The above conclusion carries over to newer analyses of possible races to the bottom, specifically in the context of international trade and independent choices of domestic labor standards. These international trade models do not have factor mobility, but similar problems can arise as goods are traded across jurisdictions. For example, the Bagwell-Staiger analysis summarized in Section 4.1 has a race-to-the-bottom interpretation, as they point out. Their model is one of imperfect competition among governments, since terms-of-trade effects are crucial to their analysis. As Bagwell and Staiger put it, "trade pressures associated with a country's WTO market access commitments could cause it to delay the introduction or enforcement of stricter labor or environmental standards." They go on to discuss how this result depends on the particular policy restrictions that are incorporated in their model. Another illustration of the sensitivity of such results lies in a comparison of Bagwell and Staiger with BDS's analysis, where standards may actually end up being inefficiently high - the opposite of a race to the bottom. 
General theoretical analyses of possible races to the bottom do not typically distinguish between different levels of development of jurisdictions. This is also true of the Bagwell-Staiger reduced form approach. On the other hand, analyses that relate terms-of-trade incentives to factor endowments can admit the interpretation of differences in development levels. For example, a country that is relatively more labor-abundant, or low-skilled labor abundant (as in BDS or Casella, respectively) can be interpreted as an developing country. Such models may also be used to analyze fears that low labor standards in developing countries (the South) may create a race to the bottom with developed countries (the North).

Chau and Kanbur (CK), take a different perspective, focusing instead on possible races to the bottom among developing country exporters to the North's markets. Their model has two large countries in the South, plus a competitive fringe, all exporting a good to the North. Labor standards have two effects in all exporting countries. They raise production costs, and they provide some utility benefit to the residents of the country (the reasons for this may have to do with altruism, conscience, etc., and are taken up in Section 5). In the model, there are two levels of labor standards, high and low. CK assume that the net gain from high labor standards is negative. Thus the competitive fringe always chooses low standards. However, for the two large exporters, there is a positive terms-of- trade effect from high standards. This implies that a high standard may lead to a higher level of welfare for a large country. ${ }^{28}$

A key aspect of the model is the nature of the strategic competition between the two large exporters, which depends on the nature of the demand curve in the importing North. Standards will either be strategic substitutes or strategic complements. ${ }^{29} \mathrm{CK}$

\footnotetext{
${ }^{28}$ Henrik Horn has pointed out that an export tax would serve the same purpose more effectively. This illustrates the earlier general point that races to the bottom typically rely on restrictions on policy instruments.

${ }^{29}$ These terms were introduced by Bulow, Geanakoplos and Klemperer (1985). In the CK model, if the inverse import demand function is logconvex, then the net gain to a country from adopting a high standard increases with the number of workers in other countries who are already under the high standard: standards are strategic complements. If instead the inverse demand function is logconcave, then standards are strategic substitutes, so that the net benefit to a country from the high standard decreases with the number of workers in other countries that have the high standard. Since the competitive fringe also enters into country welfare calculations, the size of the fringe will have similar effects to strategic choices by the other large country. While the shape of the demand curve affects the precise analysis, in either case there can be
} 
characterize the Nash equilibrium of the standard-setting game between the two large countries, for different sizes of the competitive fringe of exporters, and different relative sizes of the two large countries themselves, as well as separately for the cases of strategic substitutes and complements. Depending on the situation, the Nash equilibrium may involve low standards being set by both large countries, high standards by both, or an asymmetric outcome where the larger country chooses a high standard while the relatively smaller country chooses a low standard. The symmetric equilibria are, in fact, dominant strategy equilibria.

Can the Nash equilibrium be improved upon, and can coordination on a welfareenhancing outcome be sustained? Smaller countries are always better off with higher standards. The analysis is not extended to the welfare of the importing North, but the concern here is welfare in the South. Starting from a symmetric, low-standards equilibrium, if standards are strategic complements, the high standards outcome is better for both large countries if the labor endowment in small countries is below a critical level. In the case of substitutes, the result holds if that endowment is above a critical level. Thus the symmetric equilibrium in each of these cases represents a standard Prisoners' Dilemma problem. Starting from an asymmetric equilibrium, moving the low standard country to a high standard must involve a side payment to make it better off. Under some conditions, this will be possible, so that both countries are better off. ${ }^{30}$

CK discuss protectionism in the North, and they show that if such protectionism is precommitted, high standards equilibria become more likely. On the other hand, in the more likely case that protectionism in the North is an optimal response to Southern standards, high standards equilibria in the South will never exist. The latter conclusion acts as a warning on the use of Northern trade policy to promote standards in the South, if it is likely to end up maximizing Northern welfare. In that case, the outcome will instead

a race to the bottom, so T.N. Srinivasan's concern, in his comments, about policy relevance of such analysis, is met to some degree.

${ }^{30}$ Sustainability through repeated interaction is also considered. When the Nash equilibrium is symmetric with low standards, then in a repeated game, a high enough discount factor will sustain the high standards outcome that is better for both large countries. However, the required minimum discount factor increases as the large countries become more asymmetric in size. If the one-shot Nash equilibrium is asymmetric, there is no discount factor that will support an alternative to the static equilibrium. 
be damaging to the South's standards - note that this contrasts with the Bagwell-Staiger results, reflecting their different assumptions. On the other hand, the analysis suggests that Northern policies to promote cooperative implementation of high standards by large South exporters may be appropriate as a way of achieving that goal.

Basu (1999) also considers a model that can be interpreted as a race-to-the-bottom situation. In his model, there are multiple equilibria, and an international ban on child labor will lead to coordination on the good equilibrium (which involves a Pareto improvement), whereas the imposition of a ban by a single country will not, due to the mobility of capital. This therefore seems to be a variant of a race to the bottom. In the extreme version of this race to the bottom, there may be only one equilibrium (as in a Prisoners' Dilemma game), and one needs to change the parameters of the game to create a better noncooperative equilibrium. Alternatively, one can think of binding agreements as enforcing cooperation. This kind of possibility again raises institutional as well as conceptual issues that we discuss in the next section.

\section{Who Decides and How?}

In Section 2, we introduced and discussed different possible factors that might enter into individual value judgments about social situations. In particular, we distinguished between concerns about outcomes and about procedures. This discussion was motivated by practical lists of labor standards, which include both kinds of concerns. One general approach that encompasses both outcomes and processes involves considering individual rankings over both classes of concerns. In taking this approach, we also permit outcomes to include more than just individuals' own consumption of goods and services, and processes to encompass more than their own enjoyment of particular rights.

The question that remains is how different individuals' differing rankings of such complex alternatives are to be aggregated to arrive at an overall social ranking. For example, one person may believe that the right to collective representation and action by 
workers comes before any consideration of their wages, though given the said right, higher wages (or incomes) are considered better (and may be promoted by the exercise of the right). Another person may view material outcomes as paramount, with the right to collective action nice to have, but not essential. It may be that the set of feasible social situations does not force a sharp tradeoff between these different rankings, but on the other hand, it might. If a choice does have to be made between more rights and better outcomes, whose values should carry weight? It almost certainly should matter if one of the individuals is the worker who is affected, and the other is not. Alternatively, does it matter where the two individuals live?

In Sections 3 and 4, we have presented various reasons why outcomes might not be efficient, and some specific issues of outcomes and processes having to be balanced against each other (e.g., banning some kinds of voluntary labor contracts). In Section 3, we focused almost exclusively on problems related to the functioning of labor markets themselves. The implicit assumption underlying our discussion was that if a problem could be identified, it could potentially be fixed. For example, if banning certain kinds of voluntary contracts would benefit a majority of people, it should be possible to legislate and enforce such a ban. Here we see how a particular institution for aggregating individual rankings would be used in practice - in this case, majority rule.

In Section 4, we examined the interaction of different economies, where strategic behavior on the part of policymakers was assumed, and could sometimes lead to inefficient or undesirable outcomes. The issue here is also an aggregation problem. While national governments in such analyses are assumed to maximize some aggregate measure of the welfare of the residents of their jurisdictions, there is not necessarily any institutional mechanism for balancing the concerns of residents of different countries. In a world of perfect competition without nonpecuniary externalities, this does not matter decentralized decision-making leads to outcomes that are optimal, in the sense that no one can be made better off without making someone else worse off.

Problems arise, however, when there are imperfections in competition, externalities (including public good problems under this general heading), or both. In 
particular, caring about rights may almost require allowing for externalities, since rights are, by conception, often public or shared in nature. Finally, distributional concerns are not removed by the working of competitive markets. The upshot is that some form of international coordination in making decisions, which represents aggregation of rankings across countries, may be better than purely decentralized behavior. In this section, we explore some of the issues surrounding such international decision-making in greater depth than in previous sections, while seeking to tie possible approaches to the underlying reasons for cross-border aggregation of preferences.

\subsection{Consumption Externalities and Product Labeling}

In this subsection, we focus particularly on how individuals in general in a society view working conditions and worker rights, rather than on the direct impacts on workers themselves. In an extreme case, these approaches can be completely orthogonal. For example, an important example of a well-defined group of individuals is the consumers of a particular product. These consumers may care about how the product is made. Even if the choice of production process has no effect on the welfare or rights of workers, or on the cost of firms, if buyers care about it, and are willing to pay for it, these preferences can potentially be accounted for in the marketplace. In this case, working conditions or other aspects of how a product is made are just like a product characteristic, such as whether a shirt is red or white. On the other hand, individuals may have preferences over working conditions or worker rights that are not linked to their own consumption of the products made. This is an externality that is more difficult to accommodate through the market. We discuss both these kinds of preferences, and possible policy responses.

The possibility that labor standards can be an economic commodity has been emphasized by Freeman (1994). If consumers are willing to pay more for products made using higher labor standards, such products are essentially equivalent to "high quality" products (though fashion or other taste variables are also no different in their effects). If this quality can be directly and costlessly observed by consumers, then labor standards will be provided at the efficient level from the perspective of meeting consumer wants. 
To illustrate the argument, suppose there are two levels of labor standards, denoted by $\mathrm{s}_{\mathrm{L}}$ and $\mathrm{s}_{\mathrm{H}}$. Suppose initially that all consumers are identical, and each buys one unit of the good. An individual consumer's willingness to pay for the good is $\mathrm{u}_{\mathrm{L}}$ or $\mathrm{u}_{\mathrm{H}}$, depending on the level of labor standards used in production. If $\mathrm{u}_{\mathrm{H}}>\mathrm{u}_{\mathrm{L}}$, then the consumer is willing to pay something for the product that is made with higher labor standards.

Suppose that there are many competitive firms, each of which can choose the level of labor standards in production. The unit (average and marginal) $\operatorname{cost}$ is $\mathrm{c}_{\mathrm{L}}$ or $\mathrm{c}_{\mathrm{H}}$. It is reasonable to assume that $\mathrm{c}_{\mathrm{H}} \geq \mathrm{c}_{\mathrm{L}}$. This could conceivably hold with equality, in which case there is no problem at all. The more interesting case is where higher standards are costly to the firm. Then, with competition, firms earn zero profits, and these are the prices that prevail in the market. Consumer surplus is, therefore, either $\mathrm{u}_{\mathrm{L}}-\mathrm{c}_{\mathrm{L}}$ or $\mathrm{u}_{\mathrm{H}}-\mathrm{c}_{\mathrm{H}}$. High labor standards will prevail in the market if and only if $\mathrm{u}_{\mathrm{H}}-\mathrm{c}_{\mathrm{H}}>\mathrm{u}_{\mathrm{L}}-\mathrm{c}_{\mathrm{L}}$, that is, the extra gain to consumers outweighs the extra cost.

The market outcome is optimal if the costs of the firm properly reflect the social costs of production. On the other hand, if the firm does not take proper account of all costs, then the consumer's decision is not based on the socially optimal calculation. For example, if workers are exposed to risks that they are uninformed about, and which are not reflected in $\mathrm{c}_{\mathrm{L}}$, consumers' marketplace decisions will not necessarily capture this. Consumers are guided by market prices, which do not reflect true social costs. Note that this problem is much more general than just with respect to working conditions or other labor market issues. Any externality in production, such as pollution, or other unpriced environmental impacts, will lead to the same conclusion.

To make the point more explicitly in the context of labor standards, suppose that the benefit to workers from the higher standard is $\mathrm{v}_{\mathrm{H}}-\mathrm{v}_{\mathrm{L}}$. For the kinds of reasons discussed in Section 3, the labor market may not adequately be able to account for this worker benefit in determining the rewards and working conditions of employees, even when the gain outweighs the marginal cost, $\mathrm{c}_{\mathrm{H}}-\mathrm{c}_{\mathrm{L}}$. It may also be true that $\mathrm{v}_{\mathrm{H}}-\mathrm{v}_{\mathrm{L}}<\mathrm{c}_{\mathrm{H}}-$ $\mathrm{c}_{\mathrm{L}}$, so that worker benefits alone are not enough to justify higher labor standards. The 
higher standard is optimal in this case if the combined benefits to consumers and workers outweigh the costs, that is, $\left(\mathrm{u}_{\mathrm{H}}-\mathrm{u}_{\mathrm{L}}\right)+\left(\mathrm{v}_{\mathrm{H}}-\mathrm{v}_{\mathrm{L}}\right)>\mathrm{c}_{\mathrm{H}}-\mathrm{c}_{\mathrm{L}}{ }^{31}$ If the second term in brackets on the left hand side is zero, then we have the pure case of consumer preferences with which we began.

Returning, therefore, to the pure focus on consumer preferences, now consider the case where consumer preferences are heterogeneous. In this case, some consumers may be willing to pay more for higher labor standards, while others are not. Therefore goods may be produced both with high and with low labor standards, and consumers will buy those goods that suit their preferences. As long as information about quality is complete, there is no inefficiency in the product market.

We next consider a possible complication to the analysis. So far, we have assumed that the cost of higher standards is a variable cost. In fact, we assumed away all fixed costs, so that scale did not matter for producers. If higher labor standards are achieved through higher fixed costs, as would be the case where they involve safer or cleaner factories, for example, then the efficient scale of firms may increase. Therefore, it is possible that if there is only a small segment of consumers who are willing to pay more for higher standards, the extra cost of serving them will be quite high, reflecting the inefficient scale of the producers that serve these consumers. This is not inefficient from an allocational perspective, but simply highlights possible benefits of increasing the size of the market for goods produced according to high labor standards.

As Freeman (1994) points out, it is difficult for consumers to assess the conditions under which a product is made. This distinguishes the consumer's problem from that of the worker, in a parallel between compensating price differentials and compensating wage differentials (see footnote 31). Therefore, now consider the case where consumers cannot identify at all the labor standards used in production. Suppose that their estimate

\footnotetext{
${ }^{31}$ One might object that, to the extent that consumers' benefits do reflect workers' welfare, there is some double counting going on, but this is unavoidable. In fact, if satisfaction is shared, it presumably should count more. A related point is Freeman's observation that consumer willingness to pay for better working conditions for the worker parallels workers' willingness to pay for better conditions, which can be captured through compensating differentials. In the case of compensating differentials, some or all of the extra cost of the better working conditions may be factored into the worker's compensation.
} 
of the probability that a product was produced with low labor standards is $\alpha$. In equilibrium, this estimate should reflect the true proportion of such products. Based on this probability estimate, a consumer's expected utility is $\alpha u_{L}+(1-\alpha) u_{H}-p$, where $p$ is the price paid. Since high standard producers cannot identify themselves, they receive the same price as low standard producers. Low standard producers earn economic profit, and will enter, driving out high standard producers once the price falls below $\mathrm{c}_{\mathrm{H}}$. In equilibrium, $\alpha=1$. This is a well-known argument, and can be characterized as adverse selection or moral hazard, depending on the precise assumptions made. ${ }^{32}$

One approach to solving the information problem identified above is to use product labeling. Products can be labeled as meeting certain minimum labor standards. However, firms have an incentive to cheat, and so product labeling cannot be selfenforcing. In some markets, reputation solves the cheating problem, as consumers discover the true quality of the good after purchase. This possibility is not relevant, however, in the case of labor standards.

An alternative mechanism is third-party certification. Thus, if firms use a third party that can monitor labor standards and enforce accurate product labeling, the information problem can be overcome. In fact, if product labeling can be enforced costlessly and perfectly, it restores the full information equilibrium. More realistically, monitoring and enforcement are costly. Firms with high labor standards can pay fees to be certified to cover these costs. Such costs must then be passed on to consumers in the price of the product that is certified to have been produced with high standards.

The remaining problem here is that the certification authority now has an incentive to cheat, if such cheating cannot be detected by consumers. In this case, reputation effects will again fail to come into play. The incentive to cheat is particularly strong if the organization's objectives are profit maximization. Alternatively, if those who are responsible for monitoring and enforcement share the preferences of those

\footnotetext{
${ }^{32}$ If firms are taken to be exogenously low or high standard producers, then the situation is one of adverse selection, for which the classic reference is Akerlof (1970). If firms are assumed to endogenously decide their standards of production, then we have a moral hazard problem: one early analysis in the context of consumer preferences for quality is by Shapiro (1982).
} 
consumers who want their products made according to high labor standards, the cheating incentive is mitigated. NGOs or public agencies may fit this bill. In the latter case, the enforcement of labeling becomes a public policy matter, requiring legislation.

Finally, note that it would be prohibitively costly for an individual to monitor labor standards directly. Monitoring involves high fixed costs, and has the nonrival characteristic of a public good. However, private provision is at least possible as one method of monitoring, because free rider problems are overcome in including monitoring costs in the product price. Alternatively, we can think of NGOs and government policy as collective action mechanisms that partly overcome free rider problems: consumers then pay for the monitoring service through voluntary contributions or through taxes. ${ }^{33}$ One could also think of the firm paying the tax, and collecting it from purchasers of the "high standard" product through the higher price they pay.

At various points in the above discussion, we have introduced considerations of worker welfare, which may complement or be orthogonal to consumer concerns. We wish to emphasize that the discussion encompasses both outcomes and processes. Workers' welfare may depend not just on working conditions, but also on the rights that they enjoy. In the framework we outlined in Section 2.2, workers can have an extended ranking of different combinations of their own working conditions and rights. Consumers can also have an extended ranking of social situations that include the working conditions and the rights enjoyed by the workers who make the product they buy. This may be quite different from workers' rankings. For example, workers may only care about their working conditions, whereas consumers may only care about workers having the rights to collective action. The logic of the market is that whoever is willing and able to pay can influence the choices made.

The issue of differential willingness and ability to pay also has a bearing on the approach to implementing labor standards. In particular, if the consumers are in developed countries and the workers in developing countries, the potential for consumers to pay for their desire for better working conditions or worker rights has more scope for 
making a difference than do the preferences of relatively poor workers over the same dimensions. To the extent that a product labeling strategy makes it possible for consumers to pay, it is preferable to policies that put the burden on workers. For example, if labeling cannot be made to work, and the policy response is to ban the good that is produced under low standards, if the outcome is that the industry in the developing country shuts down, workers may be still worse off. This kind of issue is, of course, at the heart of debates about the impact of international labor standards, and we will examine it in Section 6.1. However, the point we wish to emphasize here is that policies of quantitative regulation may have very different impacts than price-based mechanisms. ${ }^{34}$

We now return to possible public good problems, which are more central when individuals care about working conditions or worker rights, irrespective of whether they purchase and consume the product or not. Thus the externality is not linked to the consumption of a product, but simply to the existence of a situation. In this case, all consumers with these preferences still should be willing to pay for improvement in labor market outcomes or processes. However, paying through the market, even with truthful labeling, is no longer sufficient for efficiency.

Consumers who do not purchase the product do not contribute payments toward improved labor standards, but receive the benefits. This is a free rider problem, which might be solved partially or completely in various ways that are used for tackling public good provision. Individuals who care might make voluntary contributions that are then used to raise standards. Alternatively, they might agree to be taxed, with the proceeds earmarked for the same purpose. If the workers who are the subject of concern are in a different country, the difficulties and costs of implementation may be great, but the economic logic points in this direction. The difficulties may be viewed as insurmountable, if the other country's political or social structure does not permit implementation. This issue of conflicting jurisdictions is taken up later in this section.

\footnotetext{
${ }^{33}$ This kind of approach is related to the proposal of Fung, O’Rourke and Sabel (2001), which we discuss in the next subsection.

${ }^{34}$ In particular, Freeman's (1994) referencing of Weitzman (1974) may not be the best analogy, since Weitzman's analysis is specific to a situation of market uncertainty, in which either price or quantity regulation may on average be better, depending on where in the market the uncertainty is greatest. In the current context, the issue is more whether consumers pay for their wants or not.
} 
One might take the view that consumers ought to care about worker rights and working conditions, irrespective of whether they purchase the products made or not. ${ }^{35}$ In other words, labor standards ought to be a public good. At one level, this argument is easy to understand. If we care about human dignity or welfare, then the importance of human rights in the workplace must not be merely dependent on consumer preferences as expressed in the marketplace. At another level, this is a difficult approach to analyze. It involves having a ranking of social situations that encompasses other individuals' rankings in the definition of social situation. In practice, individual rankings of social situations are rarely fully formed and articulated, and the political process is at least partly about resolving such issues. We take this up in the next subsection, and also in Section 6, where we, in fact, make our own argument concerning what individuals ought to care about.

\subsection{Political Economy and Collective Action}

The discussion in the last subsection, on the preferences of consumers, and of individuals in general, with respect to worker rights and working conditions, led into a consideration of how these preferences might be satisfied through collective action, in cases where the market mechanism is insufficient to achieve that objective. This is, in fact, a general problem of political economy, since one aspect of the political process and political institutions is precisely the use of collective action to determine how public goods are to be produced and paid for, how external effects are to be resolved, and what kinds of redistributions (implicit or explicit) are to be made. In fact, the usual emphasis is on how political processes are used to promote pure self-interest, rather than the interests of an altogether different set of individuals.

\footnotetext{
${ }^{35}$ One can further argue that labor rights are salient in the minds of developed country consumers precisely because such consumers now routinely buy products made in places where labor rights are lower than in developed countries. This is probably correct, but again, it does not justify this particular focus, rather than a broader concern with the general rights and welfare of those in poorer countries. Instead, one can argue that consumers need to be educated on what polices will best meet their concerns.
} 
An important example of the self-interest perspective is the possible danger that enforcing international labor standards through trade policy or related sanctions will result in concerns over human rights being 'hijacked' by interest groups that directly benefit from the enforcement of higher standards in other countries. Alternatively these interest groups may gain from the imposition of trade-related sanctions against those other countries that do not conform to the higher standards. Srinivasan $(1996,1998)$ has been most forceful in articulating the danger of hijacking, though many other economists would agree with this perspective. It is worth noting that an interest group could conceivably benefit from higher labor standards in another country, without using sanctions or trade policy in general. For example, if soccer balls produced abroad under poor working conditions are being imported to the US, competing with domestic producers, the importers could be paid to not produce, or the workers could be directly "bought off." One might view this as a form of targeted foreign aid, which happens to help a group of domestic workers and firms. Even if this seems far-fetched, such thought experiments can help to put policy alternatives in perspective.

Pahre (1998), in commenting on Srinivasan, raises the possibility that hijacking may actually help achieve a humanitarian goal. The essence of Pahre's argument is as follows. Imposing a trade sanction against a human rights violator will create domestic winners and losers, and the credibility of a threat to sanction requires that winners outnumber losers. Interest groups representing those who benefit directly (whom we may term 'protectionists'), as well as human rights groups (with the kinds of preferences we have discussed in Section 5.1), are winners if the sanction is imposed against a foreign country that does not raise its standards. This combination of groups with different motivations may create a large enough winning coalition so that the threat to sanction is credible, whereas without this coalition the policy would fail. A credible threat in this case leads to the foreign country raising its standard. If either interest group is large enough on its own, it will choose a different policy (e.g., antidumping for 'protectionists', or direct international transfers - such as were discussed above - for rights groups). International labor standards become an issue that allows the two groups to find common ground when they cannot succeed otherwise. 
Srinivasan's rejoinder to the above argument is that the central point made by Pahre is the value of credibility, not the role of protectionist interest groups. The implication is that credibility may be achieved by other, better means. However, if credibility requires a large enough coalition of supporters, a policy that benefits enough constituents is required. For example, one reason direct transfers are not used is that they do not garner enough political support. Protectionism may therefore serve a role that is difficult to finesse. Two other issues remain, however. First, is the outcome of higher standards truly better for the objects of concern, even without the imposition of sanctions? Second, is a unilateral threat of this nature, or even one that is jointly agreed to by importing nations, consistent with international norms or conventions of sovereignty? We tackle these issues below.

Pahre also suggests that second-best policies may serve a signaling role when the strength of a human rights group is unknown to the target country. For example, suppose that a sanctioning country may be of two types, one where the human rights group is large enough to tip the scales in favor of some first-best policy being supported by a majority of constituents, and the other where the rights group is not large enough to make a difference even for sanctions. In the absence of the second type, the first best policy would be used by type one, but this is subject to mimicking by the second type, which affects the credibility of the threat. The first type therefore uses the second-best policy of tying human rights to trade to make a credible threat. This seems appealing at first sight, but the nature of the first-best policy is unclear - direct transfers, for example, are not a threat.

We next return to the case of individuals who explicitly care about workers in other countries, independently of the impacts that those workers' rights and working conditions may have on the income and consumption of the concerned individuals. This category may include consumers of products made by the workers who are the object of concern, as well as human rights groups and other concerned individuals. The Pahre argument can be bypassed if the coalition of such individuals can be made large and influential enough to implement a preferred policy directly, without having to team up with 'protectionist' interests. In Section 5.1, we highlighted the argument that such 
individuals should be willing to pay for higher labor standards, including the costs of monitoring that would be required, since firms do not have an incentive to report truthfully. Alternatives to payment would be quantitative regulation. Fung, O'Rourke and Sabel (FOS, 2001) have presented a proposal that is a hybrid of monitoring through collective action, quantitative regulation, and sanctions. We next discuss some aspects of their proposal.

FOS propose monitoring by third parties, governed by a council that would represent a coalition of interests - not just concerned individuals in developed countries, but also multilateral agencies, intergovernmental organizations, NGOs, and representatives of worker interests in the organized and informal sectors of developing countries. Thus FOS are suggesting a new collective action mechanism for implementing the preferences of various groups of individuals for better working conditions and/or worker rights, rather than the "unholy" alliance of protectionists and rights advocates. In a standard political economy framework, we can characterize this as a proposal for political entrepreneurship. $^{36}$

Monitoring would be delegated to specialists, and would, if successful, lead to greater transparency and opportunities for comparison across competing producers than are available currently. However, departing from the economic logic pursued in Section 5.1, FOS suggest that sanctions be imposed on firms that either do not meet certain labor standards, as well as firms that evade monitoring altogether. Unfortunately, the nature of these sanctions is unclear. FOS suggest that sanctions should be more than civic action, but have absolutely no specifics to offer on actual institutional details of the nature and implementation of sanctions. Ultimately, therefore, the FOS proposal seems to flounder on some fundamental issues. ${ }^{37}$

\footnotetext{
${ }^{36}$ The fact that FOS propose a new kind of "club" to produce a public good is reminiscent of Casella's (1996) discussion of standards provision through voluntary coalition formation. However, in FOS's proposal, the ultimate producers of the good (firms) are explicitly not in the club, and their compliance is to be obtained by coercion.

${ }^{37}$ FOS also emphasize continuous improvement, which gives their proposal its name - Ratcheting Labor Standards. This aspect of the idea is subject to its own problems, on which see the various comments in the same issue of the Boston Review.
} 
It is also worth noting that the FOS proposal does not necessarily have any significant role for developing country governments or labor unions. They discuss the possibility that such bodies would view their council and associated monitors as substitutes for their traditional activities, and they make the counterargument that they would be complements. In practice, however, the perception of overstepping jurisdictions is likely to be a serious issue. ${ }^{38}$ The exclusion of firms from the proposed coalition of interests also poses a problem since, even though the multinational firms that are the main target in the FOS proposal care about reputation, unless it is clear that their reputations are at stake in a monetarily significant way, through the loss of sales in particular, any serious impact is unlikely. As we have noted, the implementation of sanctions on firms seems institutionally improbable. ${ }^{39}$ In fact, Bardhan (2001a) points out that the problem of competitive undercutting at the firm level - in cases where the greater willingness to pay of consumers for higher labor standards is not enough - needs to be overcome by cooperation among firms. He cites as a reasonably successful example the agreement among the main sporting goods firms, the ILO, UNICEF, NGOs and the Pakistan government to work toward eliminating child labor in the production of soccer balls. As the analyses of Basu (1999, 2001a) and Chau and Kanbur (2000) demonstrate, a further coordination issue arises at the level of nations, precisely because the firms have multinational production facilities - Bardhan also highlights this issue.

\subsection{Drawing the Line}

Cross-border externalities, whether based on consumption or on general moral concerns (where rankings may include combinations of outcomes and processes in other countries as well as one's own), raise complex issues of appropriate jurisdiction. If the residents of one political jurisdiction care about the rights or welfare of residents of another jurisdiction, what policies are appropriate to pursue? One possible pragmatic

\footnotetext{
${ }^{38}$ See the comments on FOS by Broad (2001), Levinson (2001) and Moberg (2001).

${ }^{39}$ It is not impossible that a government could pass appropriate legislation. For example, US firms are prohibited by US law from using bribery in doing business abroad. On the other hand, European firms have no such restriction.
} 
answer to the general issue of where to draw the line with respect to policy is to say that the outcomes of the democratic process properly determine how these concerns are aggregated into social policy. ${ }^{40}$ However, this does not solve the problem of what to do where the democratic decision of the citizens of the United States, for example differs from the democratic decision of the citizens of India, both with respect to the appropriate level of labor standards for Indian workers. To illustrate this issue, and possible solutions, we describe the approach taken by Dani Rodrik, and the debate it opened up.

Rodrik (1996) argues that international labor standards are justified, based on cross-border externalities such as those associated with moral considerations. His argument is as follows. He notes that citizens of developed countries have agreed, as expressed in their countries' legislation, that certain production technologies are unacceptable domestically, because workers' rights or employment conditions associated with those technologies are unacceptable. This proscription typically extends to all technologies within a country's jurisdiction, even if they involve noncitizens. Rodrik argues that importing goods from countries with unacceptably low labor standards is equivalent to importing foreign workers and allowing them to work under unacceptable conditions.

Srinivasan (1998) has countered Rodrik's argument by pointing out that there is a wide range of government regulations that affect the cost of production and the welfare of citizens in the producing country. Environmental regulations, building codes, zoning laws also differ across countries. Are goods produced in an Indian factory that does not meet United States building codes to be deemed unacceptable for import? One can extend Srinivasan's critique by noting that regulations may differ across states or regions within a country. If California has a higher minimum wage than the rest of the US, would it be morally justified in prohibiting trade with the rest of the country? Of course California cannot do so, because of the US interstate commerce clause, but the question

\footnotetext{
${ }^{40}$ A separate issue is the wide degree of variation possible in the details of democratic institutions (or even their absence), and in their consequent outcomes. A further consideration is that the democratic process also includes persuasion, for good or bad. All participants may choose to present their preferences in ways that attempt to win over other citizens. Thus arguments about what is moral or right in terms of social policy are presented, and must be evaluated, even if the final policy outcome is determined by democracy rather than logical superiority.
} 
helps to highlight the potential fuzziness of what initially seems to be a clear-cut argument.

Can one reconcile the differing positions of Rodrik and Srinivasan? Clearly, proscribing 'unacceptable' technologies indirectly by restricting the import of goods that use them cannot be a fully general argument, independent of the particular case of unacceptability. This is the point that Srinivasan makes with his counter arguments. We can bring out more explicitly two separate considerations that limit the scope of Rodrik's argument. These involve sovereignty and democracy on the one hand, and the universality or fundamental nature of human rights on the other.

First, the extension of moral concerns about rights violations involves an indirect exercise of sovereignty beyond the jurisdiction's borders. In the example of California, the state has explicitly ceded some dimensions of sovereignty to the federal government. In international trade, this issue is less clear, but the country with the lower standard has, presumably, made a sovereign decision to have that lower standard. If the democratic process in the low standard country is flawed or absent, enforcement of international labor standards may be a possible second-best response, but should be recognized as such. ${ }^{41}$ If lower standards are the result of a reasonable aggregation of the preferences of the citizens of the other country, then we may make the case that the social rankings of the citizens of India with respect to Indian labor standards should take precedence over the ranking of the citizens of the US, just as the citizens of the US should not determine what religion Indians should profess, even if they care deeply about it. ${ }^{42}$ If we accept this, then attempting to enforce international labor standards must appeal only to the second reason, which we now present.

\footnotetext{
${ }^{41}$ It is also important to point out that the incursion on sovereignty is asymmetric: the country imposing the standard does not simultaneously provide assistance to those who are adversely affected. As Panagariya $(2001 \mathrm{a}, \mathrm{b})$ points out, and as was also noted by Alan Winters in the discussion of this paper in Stockholm, this is quite different from a domestic standard, where domestic safety nets are part of the overall policy package.

${ }^{42}$ While this involves comparing two groups, it is similar in spirit to the idea that individuals should have the right to decide matters pertaining to themselves, irrespective of what others' preferences are. Recall our discussion of the "shirt colors" example in Section 2.
} 
The second justification for, as well as limitation on, Rodrik's argument is that the violation of human rights must be serious enough to warrant overriding all other considerations. The use of slave labor, prison labor, or other forced labor is typically considered abhorrent enough that issues of sovereignty and democracy are overridden. ${ }^{43}$ Thus, Rodrik's argument is really one about balancing sets of possibly competing rights, and possibly also about enforcing wider sets of rights. It is not based merely on a neutral extension of an accepted principle. Srinivasan's critique implicitly follows these lines. ${ }^{44}$ For example, the reason that Indian building codes and zoning laws are not the subject of discussion with respect to international standards is precisely because US citizens do not care about them, and probably should not care about them, in whatever rankings they have over combinations of outcomes and processes in other countries as well as their own.

Given that we are dealing with a complex problem of aggregation (usually implicit) of complex individual rankings, we should not be surprised there is no easy agreement on where to draw the line. For example, Freeman (1994), taking a selfdescribed pragmatic view, suggests that many "standards that specify processes for determining labor outcomes (freedom of association, use of slave or convict labour) ...can be met without high levels of income and thus might be viewed as fundamental social rights", which have a universal character. On the other hand, Sachs (1997) has given the example of South Korea joining the OECD, where he argues that the OECD had "no business pushing Western-European style labor relations" on the new entrant. Freeman also notes problems with being totally flexible on issues of outcome-based standards, in allowing them to vary with income. Even if we can theoretically reconcile the positions of Rodrik and Srinivasan, the practical difficulties remain, whether one is a pragmatist or not.

While we have focused our discussion of where to draw the line on the case of direct or nonpecuniary externalities, Bagwell and Staiger (2001) have shown lucidly that

\footnotetext{
${ }^{43}$ For example, as Henrik Horn has pointed out to me, forced labor is already included in the GATT (Article XX).

${ }^{44}$ Srinivasan here also expresses concern about interest group capture as a result of rights concerns: this is a separate issue that we have addressed in the previous sub section.
} 
even pecuniary externalities can matter when there is not perfect competition. Of course, this is precisely what we should expect from the theory of competitive markets. As we discussed in Section 4 of this paper, Bagwell and Staiger suggest a particular way of tying labor standards to trade negotiations, and raise the issue of drawing the line, "Why stop at labor and environmental standards? Virtually all domestic policy choices of large economies...could be the subject of an analysis similar to what we have undertaken here." Bagwell and Staiger sidestep this issue, however, by saying that the WTO "social clause" and minimum standards approach is subject to the same problem of where to draw the line, while being more invasive of sovereignty. While this certainly rationalizes the Bagwell-Staiger approach as preferable, it does not address at all the issue of what aspects of domestic standards ought to be tied in some way to international trade negotiations. Our point is that this is not a neutral decision, but involves balancing different and complex sets of rights of different groups of individuals. ${ }^{45}$

\section{What Happens to the Poor?}

If the unifying concern of those who pursue international labor standards is an improvement in the lot of those who are less well off, however this improvement is measured by different individuals, and however it is to be implemented institutionally, then the title of this section poses the central question for all those concerned. There are,

of course, further distinctions one can make in tackling this question. To what extent are we concerned about the poor in developed countries, versus in developing countries? Furthermore, what is the time horizon that we have in terms of the desired improvements?

In Sections 3 and 4, we have provided some answers to the question of the impacts of labor standards, in the context of static resource efficiency and the distribution of income. In this section, we expand on this discussion in the context of some of the 
institutional mechanisms discussed in Section 5. Next, we discuss some issues concerning the dynamics of investment in human capital, and problems created by subsistence or general resource constraints. We go naturally from these issues to examining longer run welfare issues in the context of models of endogenous innovation and growth. Finally, we return to some of the issues raised initially in Section 2, which were touched upon at several subsequent points in the paper, and discuss the role of labor standards in protecting fundamental rights of the poor. Here we suggest what we ought to care about, and put international labor standards in a broader development perspective.

\subsection{Unintended Consequences?}

One major concern that crops up repeatedly in discussions of international labor standards is whether they will have the impact that is intended. For example, in 1994, the manager of the ILO's Programme on the Elimination of Child Labor stated, "Abolishing child labor in one sector alone, such as the export sector, cannot eliminate child labor in a country - it may simply push it into other activities, including some more hazardous to children." (ILO, 1994, quoted in Freeman, 1994a). Such consequences may not be those that are intended by a policy of imposing international labor standards. On the other hand, there are cases where one may not care. If consumers in developed countries care only about how products that they consume are made, then such consequences are irrelevant. Alternatively, if the concern is with the welfare of workers in an import-competing industry in a developed country, then again, the impact on workers in developing countries is irrelevant to those concerns.

The second of the above positions is more likely to be held with some conviction. There are certainly plausible theoretical arguments that support the contention that trade between North and South can hurt the incomes of unskilled or low-skilled workers in the North. It is theoretically less clear that trade will lead to lower labor standards in the

\footnotetext{
${ }^{45}$ This point might also be applied to the Chau-Kanbur model, in which the possibility of Northern support of Southern cooperation to raise standards is raised. Implicitly, in that case, the Southern exporters are unanimous not only in their goals, but also in what they wish to include in the cooperative agenda.
} 
North, though this is also possible. We have reviewed some of these arguments in Section 4. However, it is also true that the best response to negative impacts on incomes, according to theory, is to use some form of worker adjustment assistance to deal with the impact of trade (see K.C. Fung and Staiger, 1996, and the references therein). Even in the presence of political constraints, the use of international labor standards for developing countries as a form of worker protection is likely to be relatively costly, as compared to methods based on adjustment assistance. ${ }^{46}$ In any case, the use of international labor standards explicitly to protect domestic groups violates international trade agreements as currently structured. A further, though distinct, practical counterargument is that it is unlikely that much of the harm to the poor in developed countries has come from the impacts of trade, with technological change and a rising skill premium in all likelihood playing a much greater role. ${ }^{47}$

Bardhan (2001a, 2001b) clearly argues the case that international labor standards such as banning child labor in exporting industries will only shift the problem out of the export sector. Since the proportion of overall child labor that is in export-related industries is quite low (only 5\% in India), just tackling that small proportion has, at best, no significant impact. At worst, it can significantly harm the lives of the displaced children. Similar issues arise with other kinds of labor standards that are implemented for all workers in export sectors of developing countries. Note that, in the case of child labor, the kind of analysis performed by Basu and Van (1998) and Basu (1999), in which a ban on child labor improves welfare, assumes that the ban is economy-wide. Thus the children who are displaced are taken care of, because their parents' income goes up as a result of the ban on child labor.

We illustrate this point more explicitly. The Basu-Van model assumes that adults and children can do the same work, with the latter's productivity being some fraction of that of adults. Furthermore, it assumes that a household would not send its children out to work if its income from non-child labor sources is high enough. In this model, there are

\footnotetext{
${ }^{46}$ Bardhan (2001a) notes the importance of domestic labor standards in the dimension of worker rights, where centralized collective bargaining offers more income protection to workers than decentralized unions.
} 
multiple stable equilibria. In one (see Figure 6, point $\mathrm{E}_{\mathrm{H}}$ ) there is a high wage, and adults do not have to send their children to work. In the other (point $E_{L}$ ), there is a low wage and child labor.

Figure 6: Multiple Equilibria with and without Child Labor

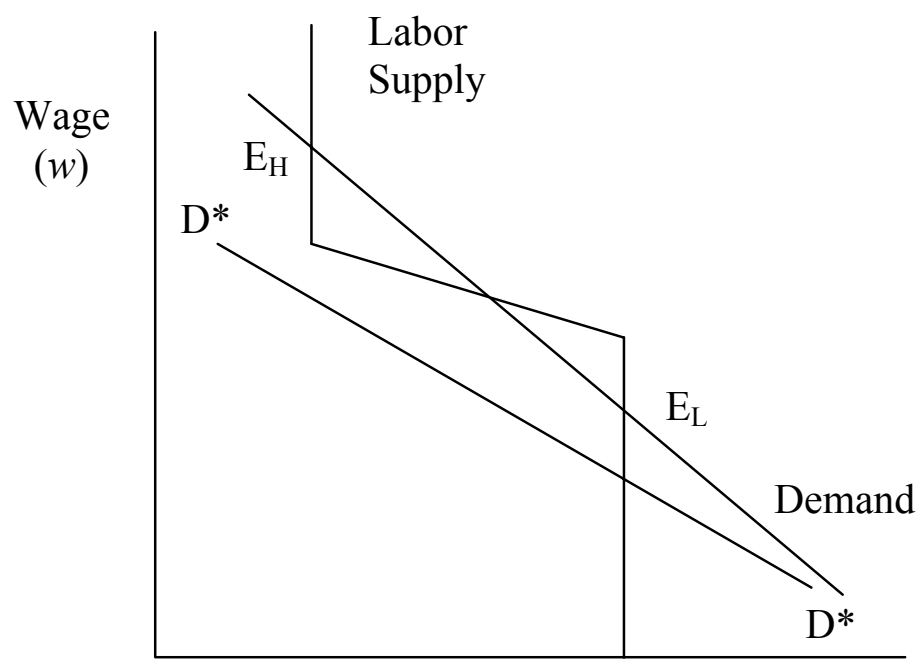

Labor

The debates about consequences extend to other examples of labor standards, including working conditions and worker rights. These debates ultimately rest on differing assumptions about competition and its effects, and on varying implicit distributional judgments. At one extreme (e.g., Rothstein, 1994) with respect to assumptions about competition is that monopsony drives a substantial wedge between marginal products and wages, as outlined in Section 3.4. In that case, there is room to extract some of the firm's excess profits, through higher wages, better working conditions, or both. On the other hand, if firms are competitive, and operate in competitive labor markets, any policy designed to improve the lot of workers will make at least some workers worse off. This is the point made by Srinivasan, Bardhan, and numerous other economists.

\footnotetext{
${ }^{47}$ See, for example, Krugman (1994). However, there is a large empirical literature that continues to try to test both sides of the argument.
} 
The mobility of capital (and the lack of international mobility of labor) poses a problem even for cases where implementing worker rights would otherwise improve workers' bargaining power, and hence their incomes (Bardhan, 2001a). When firms can relocate, the implementation of international standards requires some form of coordination among developing countries. However, coordination is probably much more difficult to achieve in the case of worker rights, as opposed to working conditions. To illustrate the point about competition and adverse consequences in another way, we can see that as the demand curve in Figure 6 becomes more elastic (curve $D^{*} D^{*}$ ), reflecting greater competition from workers elsewhere, the high wage equilibrium disappears (Dixit, 2000). ${ }^{48}$

Distributional concerns raise different issues from the negative impacts that might follow from international labor standards in the presence of competition. Even if standards improve the lot of workers in the export sector, these workers may be a privileged subset of the privileged subset of workers in the formal sector. This itself is not bad, but the distributional implication that those who are most in need of assistance according to standard welfare criteria that include a concern for equity - are not being helped, is disturbing. Other, more benign, distributional issues can also arise. In the Basu and Van model, since working households are all encompassed in the model and parents are altruistic, the fact that income is redistributed from children to adults in moving to the high wage equilibrium does not matter. In the kind of situation discussed by Bardhan, however, while there may be redistribution to poor adults (who would otherwise be unemployed) as a result of banning child labor, this must be weighed against the negative consequences on the displaced children. Baland and Robinson (2000) also point out that the high wage equilibrium in the Basu-Van model involves a redistribution away from firms - again, this is an implication that those who are concerned with equity will be comfortable with. ${ }^{49}$

\footnotetext{
${ }^{48}$ On the other hand, as T.N. Srinivasan points out in his comments, growth can move the demand curve upward, eliminating the low wage equilibrium. This is related to the discussion of growth and consequences for the poor in Section 6, especially sub section 6.3

${ }^{49}$ The issue of redistribution arises in another way in Basu and Van's model. Swinnerton and Rogers (1999) show that if workers own shares of firms sufficiently broadly, and receive dividends, the low wage
} 


\subsection{Investment in Human Capital}

With the exception of the model of Genicot (2000), treated in Section 3.7, which involves multiple periods in an essential way, we have focused on static analyses of labor standards. This is in keeping with much of the literature. In this subsection and the next, however, we examine some dynamic issues.

A dynamic structure is critical, for example, in looking at child labor, to the extent that investment in human capital by children is a central issue. Basu (1999), adapting Basu and Van (1998), models this as follows. He assumes that children and adults are perfect substitutes after adjusting for the fact that a child is a fraction of an adult in terms of productivity. He assumes that there is a unique equilibrium in a single period case, so that the Basu-Van result does not hold. The model is one of overlapping generations, where each person lives for two periods. Children can either work or go to school, and this is decided by the adult(s) in the household. Productivity, and therefore the wage as an adult is a function of human capital acquisition as a child. If the adult wage is high enough, the adult will not send the child to school, in which case the child becomes educated and earns a high wage as an adult, and so on. There can be multiple stable steady-state equilibria in this model, one where every parent sends his or her child to school and the adult wage is high, supporting this behavior, and another where every parent makes his or her child work, so that the adult wage is low. Policy intervention can move the economy toward the higher equilibrium, through a large effort to educate one generation, getting the economy out of the "child labor trap".

Baland and Robinson (2000) also examine a model in which there is a trade-ff between child labor and the accumulation of human capital. In their model, parents are altruistic, but may run out of resources needed to educate their children. The option of borrowing against their children's future income is not available to them because such

equilibrium will disappear. Basu and Van (1999) show that this would require a massive redistribution of ownership from any likely initial conditions. This issue is related to the discussion in Section 6.4. 
intergenerational contracts cannot be enforced. Besides the practicality of such contracts, they are subject to problems of moral hazard by parents borrowing against children's future income and then using the money for their own consumption. This points out some of the difficulties in relying on obvious interventions such as improving capital markets to improve education of children and reduce child labor.

The Baland-Robinson model leads to an equilibrium that is Pareto inefficient, even without the existence of positive externalities to human capital accumulation - an idea that has been pursued by Grootaert and Kanbur (1995). The idea that subsistence and capital market constraints on households force children into work seems empirically plausible, and more compelling than an argument based on social returns exceeding private returns. Baland and Robinson also examine endogenous fertility decisions by parents. They show that the general impact of a reduction of child labor on fertility is ambiguous, though under special circumstances, the effect is to reduce fertility. This latter result was also obtained by Eswaran (1996), who showed that when parents need children for old-age security, allowing child labor could induce parents to have larger, but less-educated families. The advantage of the Baland-Robinson analysis is a clear-cut welfare ranking of possible outcomes.

If, as in the Baland and Robinson analysis, child labor is Pareto inefficient, why is it difficult to abolish in practice? The answer that they provide to this question is that heterogeneity may create some losers from a ban, necessitating compensatory transfers that are themselves infeasible or costly to implement. For example, rich people and those firms that have adopted technologies that do not require skilled workers may be affected by a ban, the former by having their wages depressed, the latter by being put at a competitive disadvantage. In the absence of such factors, however, government subsidies of education, financed by a tax on adult earnings, could be Pareto-improving. Baland and Robinson also suggest that foreign bans on imports of goods produced with child labor can be Pareto-improving, but this assumes away some of the problems noted by Bardhan (2001a) and others, as discussed in the previous subsection. ${ }^{50}$

\footnotetext{
${ }^{50}$ Additional analysis of child labor issues may be found in Brown (2000c) and Brown, Deardorff and Stern (2001).
} 


\subsection{Long Run Effects}

Investment in human capital is relevant for all workers, not just for children, though it is particularly important in their case. Thinking about retraining and education naturally leads one to a more general discussion of long run issues in weighing labor standards. Long run development can depend on technological change as well as on investment. Piore $(1990,1994)$ argues that there can be multiple equilibria in an economy, and that labor standards can move firms and workers out of a "sweatshop" equilibrium. This much is similar to our earlier discussion of multiple equilibria with a subsistence constraint. Piore goes on to suggest that forcing up labor costs induces technological change and growth.

The induced technological change hypothesis is an old one, but it is hard to justify formally. If profitable opportunities for technological improvement exist, then the firm should be able to take advantage of them irrespective of its current strategy. Tying technological change to current or past factor intensities requires either some kind of localized learning about possible innovations, switching costs that lock the firm into its current technology, or some other reason for path dependence. ${ }^{51}$ Alternatively, there must be some positive externality associated with the high wage equilibrium that fuels growth. For example, if workers are better off than the subsistence level of income, they may be able to invest in their own or their children's education. ${ }^{52}$ Consumers, who are worse off in the high wage equilibrium, may simply curtail consumption of goods that do not affect growth. This simply brings one back to the kinds of models analyzed by Basu and Baland and Robinson.

\footnotetext{
${ }^{51}$ See the discussion of these issues in the context of development in Singh (1994) and Marjit and Singh (1995).

${ }^{52}$ Piore seems to make the human capital argument as well. See also the discussion of Ellingsen's comments at the end of this sub section.
} 
Explicit models of growth appear not to have been considered in the literature on international labor standards. However, Amsden (1995) provides a discussion based implicitly on a structuralist model of developing country economies and their growth. Amsden distinguishes between "wage-led" growth, in which real wages rise with productivity, and this fuels aggregate demand, investment and ultimately higher incomes, and "profit-led growth", in which profits are the source of investment and growth. The former economies are identified with large countries that have substantial domestic markets, while the latter are equated to smaller, open economies. Amsden argues that international labor standards would be consistent with, and might even support, wage-led growth, but that they would very probably hurt growth in small, open developing country economies. While Amsden does not provide a full model, she appears to be assuming that there are some structural rigidities or imperfect competition effects, which can create a wedge between real wages and marginal products. Growth is assumed to be determined by investment, and there is no role for endogenous technological progress.

One possibility for formally examining the relationship between labor standards and growth that would allow for endogenous technological progress (as highlighted by Piore) is to use the framework of Grossman and Helpman (1991, Ch 10). For example, they consider a two-country model where each country has three sectors: traditional manufacturing, high-tech manufacturing, and $R \& D$, in order of increasing human capital intensity. R\&D ultimately determines innovation and growth, and it is not surprising that a subsidy to R\&D in one country increases its rate of innovation and growth.

Production subsidies are more surprising in their effects. A production subsidy to the high-tech sector reduces innovation and growth, because it draws human capital (skilled labor) from the R\&D sector. A production subsidy to the low-tech sector in one country spurs growth in that country, but at the expense of the other country. If we interpret a labor standard as analogous to a tax on the low-tech sector, which uses low skill labor more intensively, then the Grossman-Helpman analysis suggests that a labor standard would actually be harmful to growth in the country where it is applied, and therefore to the long run welfare of low skill workers in that country. This perspective would suggest some caution in accepting Piore's assertions on labor standards and 
growth, though alternative models might bear out his analysis. Note that the imposition of an international labor standard on the low-tech sector of the country with relatively less human capital would seem to cause long term harm to that country's growth, if the analogy with a tax is reasonable.

In another way, the results of the thought experiment of introducing labor standards into the endogenous growth model are not surprising. Growth in that model is driven by technological progress, and there is nothing tying technological progress to working conditions, or to worker rights. Piore tries to make this connection through a discussion of firms' business strategies, but the argument is ultimately unclear. The detailed modeling of firm decision-making along the lines discussed in Milgrom, Qian and Roberts (1991) might provide some insights. Tore Ellingsen, in his comments, also provides a hint of a fruitful approach in this area. He points out that, in an incomplete contracting framework, such as that analyzed by Grossman and Hart (1986) and Hart and Moore (1999), workers with no rights may be reluctant to invest in firm-specific human capital (and, to extend the argument, firm-specific innovation). Thus assigning some control rights to workers might have positive impacts on efficiency and growth.

\subsection{Rights and the Poor}

One of the distinguishing features of the debate on international labor standards is its emphasis on human rights in general, and on the rights of the poor in poor countries, in particular. The emphasis on rights poses some difficulties for standard welfare economics but, as we have indicated in Section 2.2 and subsequent discussions, these difficulties are not insurmountable for a rigorous and consistent analysis, incorporating concerns about rights or processes as well as outcomes or consequences.

If we accept that fundamental rights, including labor rights, are of overriding importance in themselves, then improving the extent to which all workers enjoy such rights provides immediate and lasting benefits. This argument in favor of fundamental rights is almost tautological. The practical difficulty, as we have seen, comes about in 
deciding where to draw the line around fundamental rights. Debate is particularly useful here, because it can clarify which rights are to be considered fundamental, and it can help to achieve something that approaches a consensus. The ILO/OECD core labor standards are not necessarily the final word on this topic, as Fields (1995) lucidly argues. In any case, it is typically the poor in every country whose rights deserve the most protection, so a general strengthening of concern for fundamental rights would presumably help them the most.

However, there is a further difficulty that might work against the last statement: a concern for rights may conflict with outcome-based measures of welfare. This is a fundamental problem in the abstract, with regard to situations where preferences are other-regarding, as illustrated by the conflict between the Pareto principle and libertarian rights (Sen, 1970), or variants of it (the "shirt colors" example in Section 2.2). More concretely, for example, enforcing strict rights of collective bargaining can conceivably deter hiring, and make workers worse off through job loss. We might still argue that such a right is important enough that it must transcend narrow welfarist considerations: this case is easy to accept for prohibitions against slavery or bondage, even if "voluntary".

A further response could be that in such cases it is not sufficient to enforce the labor right in isolation - human beings are entitled to a set of minimum rights that must be provided or ensured as a bundle. If this bundle of rights includes access or entitlement to sufficient education and credit opportunities, the poor person's bargaining power is increased in a manner that mitigates the possible adverse effect of labor rights. ${ }^{53}$ In many poor countries, an even more basic right that is still not universally available is the right to some minimum level of physical or biological well-being. Lack of adequate nourishment and unwarranted exposure to various hazards are examples of a failure to meet such minimum standards.

\footnotetext{
${ }^{53}$ One might even argue that sufficient access to education and credit make the satisfaction of rights automatic. For example, Silicon Valley engineers are well treated because of their skills, and not because of any labor rights that they are endowed with by law. This cannot be general counter argument, however, since it involves a somewhat extreme case of skills, and even such workers need to be informed about potential job hazards, or protected from certain kinds of restrictive labor contracts.
} 
In highlighting such an approach, we are not being particularly novel. Sen (1985a, 1985b) has developed and emphasized the importance of human capabilities in thinking about the objectives of development. Dasgupta (1993), and Ray (1993, 1998, see also Ray and Streufert, 1993) have examined the importance and consequences of nutritional deprivation. Numerous authors and developmental institutions have emphasized the crucial need to "invest in people", based on a tripartite framework that includes nutrition, skills, and financial assets. ${ }^{54}$ In such cases, again, we are emphasizing capabilities, which may include endowments as well as rights, along with outcomes.

How does this impact the debate on labor standards? We suggest that those who care about worker rights and working conditions of the poor in poor countries ought to do so in a broader context. If the fundamental rights at stake are the ability to achieve minimum standards of physical and mental well-being, ${ }^{55}$ narrowly focusing on labor standards may not be the right approach to thinking about rights. One needs a broader perspective. To illustrate this concretely, consider once again the case of child labor. Bardhan (2001a, 2001b) reviews several different policies that can be and have been tried to tackle this issue, including making schools more attractive or less costly to attend, having firms employing child labor finance some of these efforts, improving the productivity of adult workers in the same industry, and so on. The point is that the focus is on the broader rights and welfare of the children, rather than on child labor per se. Of course unsafe and unhealthy working conditions are still to be controlled, but this is again properly part of a broader concern with physical well-being. It is the fundamental rights to capabilities that enable achievement of minimum well-being that individuals, whether in developed or developing countries, ought to care about. ${ }^{56}$

\footnotetext{
${ }^{54}$ For a comprehensive "textbook" treatment, see Ray (1998). For an overview with recent examples, placed in the context of globalization, see Bardhan (2001a).

${ }_{55}$ Note that in accepting this position, rights advocates are not too far from T.N. Srinivasan's philosopher friends (see his comments) who agree that it is "virtually impossible to rank processes without considering their potential consequences." In the example at hand, consequences are built in to the rights that are classified as fundamental. On the other hand, freedom to choose remains a process-based right. Srinivasan's comments about the importance of social and temporal context are relevant here. See Section 5.3 as well.

${ }^{56}$ Of course, this does not have to diminish concern about rights such as freedom of speech and association: any supposed trade-off between these is likely to be a false one. I am grateful to Ulf Edström for bringing out this point in the discussion at the seminar.
} 
All this is not to say that labor standards are unimportant, merely that they must be placed in perspective. In general, the interaction of the credit and education markets with the labor market provides examples of how labor standards may be beneficial, or alternatively, where the policy focus may need to be different. In Genicot's (2000) analysis of bonded labor, restricting one set of voluntary contracts that may be signed can actually help poor workers because it allows another, more attractive set of credit contracts to become available. An alternative approach might be to improve the working of rural credit markets through micro-credit schemes or similar approaches. In the Baland-Robinson (2000) analysis, the credit market imperfection cannot be directly removed to make it possible for parents to finance their children's education and avoid child labor. Banning child labor may solve the problem in the theoretical model, but in practice, targeted subsidies for education for the poor may be a good alternative policy.

The same policies that improve basic capabilities, through access to minimum levels of physical well-being, education, and credit opportunities, are likely to be quite consistent with concerns about outcomes alone. To the extent that outcomes include educational outcomes, the correlation is obvious. Even if we care only about low incomes, and measure poverty accordingly, improving access to nutrition, education and credit may be the proper primary areas of policy focus, rather than labor standards. For example, job provision or protection schemes typically work less well than policies aimed at more fundamental capabilities, even if efficient targeting in the presence of incomplete information requires in-kind rather than cash transfers. ${ }^{57}$ These observations are just as true for developed countries as they are for developing countries, and it is safe to say that they reflect the thinking of most economists, whatever weight they put on nonconsequentialist concerns in their own views.

\footnotetext{
${ }^{57}$ See Singh and Thomas (2000) for such an analysis.
} 


\section{Conclusion}

In this conclusion, we summarize our main arguments. This survey has gone beyond the issue of linking labor standards with trade, to review key economic arguments in favor of labor standards. As the comments by Srinivasan and Ellingsen have suggested, even this attempt has not been comprehensive. However, we have accomplished several things in this paper.

Methodologically, we showed how value judgments and normative concerns about rights can be rigorously incorporated into discussions of international labor standards. In fact, rigor helps in bringing out the potential conflicts or tradeoffs between outcomes and processes. After setting the methodological stage, we reviewed at least a significant subset of possible labor market problems, what their consequences might be in terms of worker welfare, how to evaluate them in terms of labor market processes, and finally, what the impacts might be of different interventions that come under the broad heading of "labor standards". The general conclusion of this survey of models of the labor market is a familiar one for economists: there are many potential sources of market failure, and devising policies to correct them can be complex and circumstance specific. Nevertheless, careful economic analysis can aid in appropriate policy choices, whatever the objectives may be (including concerns about processes).

We next considered a range of economic models that place (international or domestic) labor standards in the context of the global economy. Again, impacts are often model-specific, and this suggests that international labor standards policies must be applied with caution, even policy coordination issues are at the heart of the problem. Even when cooperation on international labor standards may be desirable, the case for linking standards to trade negotiations remains problematic. We then turned to the contentious questions of "who decides and how?" in the context of international labor standards. Our discussion highlighted the importance of explicitly recognizing the value judgments being made, issues of collective action, and those of sovereignty. 
Our final topic was the impact of international labor standards on the poor, and here we reviewed some of the possibilities raised earlier in the paper, as well as some new issues. We examined the case that international labor standards can end up hurting those they are supposed to help, unless they are part of a broader policy package. We linked this to an argument that the proper concern, even where processes matter as well as outcomes, is with a more basic set of capabilities and rights than is typically encompassed by proponents of international labor standards. Policies that promote basic nutrition and health, and broader access to education and credit are likely to help growth, as well as having intrinsic benefits. Our final conclusion, therefore, is that this is what individuals and policy-makers ought to care about, rather than labor standards in isolation. Labor standards may well be a component of such policies, but must be implemented in context. 


\section{Appendix 1}

\section{Basic Competitive Model}

We model a worker's utility as being a function of a vector of market-purchased consumption goods $(\boldsymbol{x})$, leisure $(l)$, and a vector of nonpecuniary job characteristics $(\boldsymbol{s})$, so that the function is $u(\boldsymbol{x}, l, \boldsymbol{s})$. We assume that job characteristics are defined and measured so that "more is better" always. Thus the function is increasing in all its arguments. The worker has an endowment, $T$, of time, and receives a wage, $w$, which she takes as given. She chooses how much to work at this wage, and how much of the various consumption goods to buy with her earnings from work, but job characteristics are taken as given. Then her maximization problem is described as

$$
\begin{aligned}
& \max _{x, l} u(\boldsymbol{x}, l, \boldsymbol{s}) \\
& \text { subject to } \boldsymbol{p} \cdot \boldsymbol{x}=w(T-l),
\end{aligned}
$$

where $\boldsymbol{p}$ is the vector of goods prices.

In this formulation, the individual's labor supply decision in terms of time receives attention, as well as how income is spent, but the characteristics of the job are not in the individual's choice set. The above maximization will give demand functions for goods and a supply function for labor, which can be substituted in the objective function to yield the indirect utility function, denoted by $v(\boldsymbol{p}, w, T, \boldsymbol{s})$. This is the maximum utility that the worker can obtain given the existing market conditions. If market prices of consumption goods are taken as given, we can suppress them in the arguments of the indirect utility function. Furthermore, we can suppress the individual's time endowment, since this is determined by nature. Hence the indirect utility function can be written as $v(w, s)$.

Now consider the decision-making of the competitive firm producing the single consumption good. If it chooses total labor and capital to maximize profits, given wages and prices, it solves the following maximization problem 


$$
\begin{aligned}
& \max Q-w L-r K \\
& L, K \\
& \text { subject to } Q=F(L, K, \boldsymbol{s}),
\end{aligned}
$$

where $r$ is the rental rate (price of capital) and $F(L, K, \boldsymbol{s})$ is the production function. ${ }^{58}$ This problem will yield demand functions for labor and capital. We focus on labor only, suppressing the role of the rental rate and the market for capital. In that case, the wage rate can be viewed as determined by the equality of supply and demand for labor. ${ }^{59}$ If there are $n$ firms and $N$ workers, then this condition is simply

$$
N h^{S}(w, s)=n L^{D}(w, s),
$$

where $h^{S}(w, s)=T-l^{S}(w, s)$ is the labor supply function of an individual worker. For the above equation to determine the wage rate, both $N$ and $n$ must be determined. We can simply assume that each of them is exogenous. Alternatively, the number of firms may be determined by a zero profit condition, implied by free exit and entry in competition. In that case the labor market clearing and zero profit conditions simultaneously determine the wage rate and the number of firms. Of course, with constant returns to scale, the number of firms is indeterminate, since profits are always zero.

\section{Appendix 2}

\section{Firms Decide Working Conditions}

Suppose that the cost of a level, $s$, of the index of working conditions is $c(s)$, a differentiable, convex, strictly increasing function. Furthermore, suppose that there is some minimum level of $\mathrm{s}$ that is technologically feasible, say $s_{0}$. The firm's maximization problem is now

\footnotetext{
58 There is, of course, no difficulty in adding more inputs or incorporating fixed costs into this formulation.

${ }^{59}$ More generally, the wage and rental rate can be taken as simultaneously determined by the supply and demand of labor and of capital. Even more generally, there are multiple markets for labor, capital and goods that all clear simultaneously. We are taking a simple partial equilibrium view here.
} 


$$
\begin{aligned}
& \max Q-w L-r K-c(s) \\
& L, K, s \\
& \text { subject to } Q=F(L, K, s) \text {, } \\
& \text { and } \quad s \geq s_{0} .
\end{aligned}
$$

If the inequality constraint is not binding, we get the straightforward condition that marginal benefit equals marginal cost, or $F_{s}=c^{\prime}$, as determining the job characteristic (where the subscript denote the partial derivative). Clearly the left-hand side of this marginal condition depends on $L$ and $K$, so these are determined simultaneously with $s$, by the marginal conditions for input choice. In fact, from the firm's perspective, labor, capital and working conditions are all inputs into its production. The difference in the case of working conditions is that these will typically directly affect the worker's welfare, and the firm does not take this into account in its calculations.

The above formulation assumes that the cost of providing a given level of working conditions is independent of the firm's other choices. This assumption can be relaxed. For example, the cost function for working conditions may be $c(s, L, K)$. For example, having more equipment or more workers can raise the cost of providing a safe factory. In this case, the simultaneity of determination of $L, K$ and $s$ is also driven by this cost function, as well as the production function with the first-order condition becoming $F_{s}=c_{s}$, the right hand side now being a partial derivative.

\section{Competitive Demand and Supply of Working Conditions}

Suppose that each worker can individual choose her working conditions, and their level, $s$, does not affect productivity. Let us also suppose that there is a competitive market in $s$. For example, there may be competing specialists that provides such features to all firms. Let the price of the good be $m$. Now each worker can purchase $s$ in the marketplace, so her maximization problem is 


$$
\begin{aligned}
& \max u(x, l, s) \\
& x, l, s \\
& \text { subject to } x+m s=w(T-l),
\end{aligned}
$$

Suppliers of $s$ maximize $m s-c(s)$, so that in equilibrium we get $u_{s}=c^{\prime}$, which, together with the price-taking choices of $x$ and $l$, is optimal, through the standard market mechanism of price mediation. Hence, if job characteristics do not affect productivity, and they are competitively supplied, we get the optimal outcome.

\section{Compensating Differentials}

Suppose that firms' maximized profits (with respect to labor and capital inputs) given $w$ and $s$ are denoted by $\pi(w, s)$, where the dependence on the rental rate is suppressed. Suppose that competition by firms for workers is such that firms offer wage and job characteristic combinations that maximize workers' welfare, subject to a nonnegativity constraint on profit. Free entry will make this constraint bind, i.e., profits will be zero in equilibrium. That is, the firm maximizes workers' indirect utility $v(w, s)$ subject to $\pi(w, s)=0$. In this case, we are assuming that the firm hires one worker, or that all workers it hires are identical. As noted in the main text, this formulation is not competition in the sense of price-taking behavior. Let the multiplier associated with the constraint be $\lambda$. Then the first order conditions for the equilibrium are:

$$
\begin{aligned}
& v_{w}+\lambda \pi_{w}=0, \text { and } \\
& v_{s}+\lambda \pi_{s}=0 .
\end{aligned}
$$

Thus we see that in this case, $\mathrm{s}$ is chosen to maximize a weighted sum of the worker's utility and the firm's profit. This will be equivalent to maximizing the sum of profit and utility if $\lambda=1$. In any case, the wage and job characteristic combinations that result are optimal, in the sense that the worker's utility cannot be increased without causing firms to make losses and become nonviable. We may also work out the marginal expressions 
in terms of the underlying utility function and production function. From the envelope theorem applied to $v$ and $\pi$, we have that:

$$
\begin{array}{ll}
v_{w}=u_{x}(T-l(w, s)) & \pi_{w}=-h^{D}(w, s) \\
v_{s}=u_{s} & \pi_{s}=F_{s}-c^{\prime}(s) .
\end{array}
$$

The above formulation results in firms offering different wage and job-type combinations to workers who have different tradeoffs between money income and job characteristics. Since firms are competing for workers, even if they hire multiple workers, the above result will still hold, with the firm maximizing the sum of the utilities of its workers, subject to the zero profit constraint. Even if workers are heterogeneous in their preferences, the firm's decisions yield Pareto optimality. Explicitly, the firm maximizes

$$
\sum_{i} v_{i}\left(w_{i}, s\right) \text { subject to } \pi(\boldsymbol{w}, s)=0 \text {. }
$$

This is a standard problem in allocating a public good. In this formulation, the firm is constrained to offer the same level of $s$ (the public good) to all its workers, but it can adjust its wage offers based on workers' preferences. With many competing firms, as discussed in the main text, one can get sorting of workers so that workers with similar preferences ( $w-s$ tradeoffs) work for the same firm. This is, in fact, very similar to Tiebout-type models of competing jurisdictions, where local governments set taxexpenditure policies to attract residents. The original reference is Tiebout (1956)

\section{Appendix 3}

\section{Monopsony}

For simplicity, we can consider the case of one worker, and we can suppress the analysis of the firm's choice of capital. We use the notation given in Appendix 1 for the worker's supply of labor, which also depends on the level of working conditions. Hence the firm chooses $w$ to maximize 


$$
\begin{aligned}
& F\left(h^{S}(w, s), s\right)-w h^{S}(w, s), \text { which yields the first order condition } \\
& F_{L} h^{S}{ }_{w}=h^{S}+w h^{S}{ }_{w} .
\end{aligned}
$$

This condition implies that the value of the worker's marginal product exceeds her wage rate. Now if the firm also chooses the level of working conditions in a similar fashion, the first order condition is

$$
F_{L} h_{S}^{S}+F_{S}=w h_{s}^{S}+c^{\prime}
$$

Note that if the firm were setting the wage equal to the marginal value product, the first term on each side of this equation would be equal and cancel out, and we would get the optimality condition for the choice of the job characteristic level. Since the wage is below the value of the marginal product, it follows that $F_{s}<c^{\prime}$. If job characteristics did not enter the utility function of the worker, this would imply that the level of the job characteristic is also nonoptimal - but too high - given the wage rate. In actuality, since the optimality condition is $u_{s}+F_{s}=c^{\prime}$, and using the first order condition for $w$, the appropriate comparison is of $u_{s}$ with $h^{S} h^{S}{ }_{s} / h^{S}$. This comparison is indeterminate. 
The Impact of International Labor Standards: A Survey of Economic Theory

Nirvikar Singh, Department of Economics, University of California, Santa Cruz. Final Version, October 2001.

\section{References}

Aghion Philippe and Benjamin Hermalin (1990), Legal Restrictions on Private Contracts Can Enhance Efficiency, Journal of Law Economics and Organization, 6, 2, 381-409.

Akerlof, George (1970), The Market for Lemons: Quality Uncertainty and the Market Mechanism, Quarterly Journal of Economics, 84, 488-500.

Akerlof, George (1976), The Economics of Caste and of the Rat Race and Other woeful Tales, Quarterly Journal of Economics, 90, 599-617.

Amsden, Alice (1994), Hype or Help?, Boston Review, 20,1, December -January.

Bagwell, Kyle and Robert Staiger (2000), The Simple Economics of Labor Standards and the GATT, Chapter 7 in Deardorff and Stern, eds., 2000.

Baland Jean-Marie, and Robinson, James (2000), Is Child Labor Inefficient?, Journal of Political Economy, 108, 4, August, 663-679.

Bardhan, Pranab (2001a), Social Justice in the Global Economy, Economic and Political Weekly, February 3-10.

Bardhan, Pranab (2001b), Some Up, Some Down, Boston Review, 26,1, February-March.

Basu, Kaushik (1999), Child Labor: Cause, Consequence, and Cure, with Remarks on International Labor Standards, Journal of Economic Literature, 37, September, 1083 1119.

Basu, Kaushik (2001a), On the Goals of Development, in Frontiers of Development Economics: The Future in Perspective, Gerald Meier and Joseph Stiglitz, eds., Washington, DC: World Bank and Oxford University Press.

Basu, Kaushik (2001b), The View from the Tropics, Boston Review, 26,1, FebruaryMarch.

Basu, Kaushik, and Van, Pham Hoang (1998), The Economics of Child Labor, American Economic Review, 88, 412-427.

Basu, Kaushik, and Van, Pham Hoang (1999), The Economics of Child Labor: Reply, American Economic Review, 89, 5, 1386-1388.

Berlin, Isiah (1969), Four Essays on Liberty, Oxford: Oxford University Press.

Bhagwati, Jagdish (1995), 'Trade Liberalization and 'Fair Trade' Demands: Addressing Environmental and Labour Standards Issues', World Economy, 18.

Bhagwati, Jagdish and Robert Hudec, eds. (1996a,) Fair Trade and Harmonization, Vol. 1: Economic Analysis, Cambridge MA: MIT Press. 
Bhagwati, Jagdish and Robert Hudec, eds. (1996b), Fair Trade and Harmonization, Vol. 2: Legal Analysis, Cambridge MA: MIT Press.

Bhagwati, Jagdish and T.N. Srinivasan (1996), Trade and the Environment: Does Environmental Diversity Detract from the Case for Free Trade?, in Bhagwati and Hudec, eds., 1996a.

Broad, Robin (2001), A Better Mousetrap?, Boston Review, 26,1, February-March.

Brown, Drusilla (2000a), International Labor Standards in the World Trade Organization and the International Labor Organization, Discussion Paper 2000-03, Department of Economics, Tufts University.

Brown, Drusilla (2000b), International Trade and Core Labor Standards: A Survey of the Recent Literature, Discussion Paper 2000-05, Department of Economics, Tufts University.

Brown, Drusilla (2000c), A Transactions Cost Politics Analysis of International Child Labor Standards, Chapter 8 in Deardorff and Stern, eds., 2000.

Brown, Drusilla, Alan Deardorff and Robert Stern (1996), International Labor Standards and Trade: A Theoretical Analysis, in Bhagwati and Hudec, eds., 1996a.

Brown, Drusilla, Alan Deardorff and Robert Stern (1997), Issues of Environmental and Labor Standards in the Global Trading System, Working Paper 97-10, Department of Economics, University of Michigan.

Brown, Drusilla, Alan Deardorff and Robert Stern (2001), Child Labor: Theory, Evidence and Policy (this volume).

Bucovetsky, S. and John D. Wilson (1991), Tax Competition with Two Tax Instruments, Regional Science and Urban Economics, 21, 333-350.

Bulow, Jeremy, Geanakoplos, John and Klemperer, Paul (1985), Multimarket Oligopolies, Journal of Political Economy.

Casella, Alessandra (1996), Free Trade and Evolving Standards, in Bhagwati and Hudec, eds., 1996a.

Chau, Nancy and Ravi Kanbur (2000), 'The Race to the Bottom, From the Bottom, Working Paper, Cornell University, November.

Cornes, Richard and Sandler, Todd (1986), The Theory of Externalities, Public Goods, and Club Goods, Cambridge: Cambridge University Press.

Dasgupta, Partha (1993), An Inquiry into Well-Being and Destitution, Oxford: Clarendon Press. 
Datta, S. and P.R. Chowdhury (1998), Management Union Bargaining under Minimum Wage Regulation in Less Developed Countries, Indian Economic Review, 33, 2, 169-84.

de Waart, Paul (1996), Minimum Labour Standards in International Trade from a Legal Perspective, in van Dijk and Faber, eds.

Deardorff, Alan and Robert Stern, eds. (1998), Constituent Interests and U.S. Trade Policies, Ann Arbor: University of Michigan Press.

Deardorff, Alan and Robert Stern, eds. (2000), Social Dimensions of U.S. Trade Policies, Ann Arbor: University of Michigan Press.

Dickens, William (1984), Occupational Safety and Health Regulation and Economic Theory, in Labor Economics: Modern Views, ed. William Darity, Jr. Boston: KluwerNijhoff.

Dixit, Avinash (2000), Comment on A Transactions Cost Politics Analysis of International Child Labor Standards, Chapter 8 in Deardorff and Stern, eds., 2000.

Enders, Alice (1996), The Role of the WTO in Minimum Standards, in van Dijk and Faber, eds.

Engerman, Stanley (2001), The History and Political Economy of International Labor Standards (this volume).

Eswaran, Mukesh (1996), Fertility, Literacy and the Institution of Child Labor, manuscript, Vancouver: U. of British Columbia, Department of Economics.

Fairris, D., (1995), Do Unionized Employers Reappropriate Rent through Worsened Workplace Safety, Eastern Economic Journal, 21, 2, 171-85.

Fields, Gary (1996), Trade and Labour Standards: Final Report on the Meeting, Working Paper No. 7, Paris: Organization for Economic Cooperation and Development.

Fields, Gary (2000), The Role of Labor Standards in U.S. Trade Policies, Chapter 6 in Deardorff and Stern, eds., 2000.

Freeman, Richard (1994), A Hard-Headed Look at Labor Standards, in US Department of Labor.

Freeman, Richard (1994), A Hard-Headed Look at Labour Standards, in Sengenberger and Campbell.

Fung, Archon, O’Rourke, Dara and Sabel, Charles (2001), Realizing Labor Standards, Boston Review, 26,1, February-March. 
Fung, Kwok-Chiu, and Staiger, Robert (1996), Trade Liberalization and Trade Adjustment Assistance, in The New Transatlantic Economy, Canzoneri, M., W. Ethier and V. Grilli, eds., Cambridge: Cambridge University Press.

Genicot, Garance (2000), Bonded Labor and Serfdom: A Paradox of Voluntary Choice, Working paper, University of California, Irvine.

Golub, Stephen (1997), Are International Labor Standards Needed to Prevent Social Dumping?, Finance and Development, December, 20-23.

Golub, Stephen (1997), International Labor Standards and Trade, Working Paper WP/97/37, Research Department, International Monetary Fund.

Grootaert, Christiaan and Kanbur, Ravi (1995), Child Labor: An Economic Perspective, International Labor Review, 134,2, 187-203.

Grossman, S., and O. Hart (1986) The Costs and Benefits of Ownership: A Theory of Vertical and Lateral Integration, Journal of Political Economy, 94, 691-719.

Grossman, Gene and Elhanen Helpman (1991), Innovation and Growth in the Global Economy, Cambridge, MA: MIT Press.

Hart, Oliver and John Moore (1999), Foundations of Incomplete Contracts, Review of Economic Studies, 66, 1, 115-138.

ICFTU (1999), 'Development, Environment and Trade: Statement to the High-level Symposia of the WTO on 'Trade and Environment', Geneva, 15-16 March 1999', mimeo: ICFTU, Geneva and Washington.

ILO, Washington Branch (1994), Washington Focus, Spring, p. 9.

Krugman, Paul (1994), Does Third-World Growth Hurt 1st World Prosperity?, Harvard Business Review, 72, 4, 113-121.

Levinson, Mark (2001), Wishful Thinking, Boston Review, 26,1, February-March.

Lindbeck, Assar (1988), Individual Freedom and Welfare State Policy, European Economic Review, 32, 295-318.

Marjit, Sugata and Singh, Nirvikar (1995), Technology and Indian Industry, in Indian Industry, Dilip Mookherjee, ed., New Delhi: Oxford University Press.

Maskus, Keith (1997), Should Core Labor Standards be Imposed through International Trade Policy, Paper prepared for World Bank International Trade Division.

Milgrom, Paul, Qian, Yingyi and Roberts, John (1991), Complementarities, Momentum, and the Evolution of Modern Manufacturing, American Economic Review, May, 81, 2, 84-88. 
Moberg, David (2001), Unions and the State, Boston Review, 26,1, February-March.

Nozick, Robert (1974), Anarchy, State and Utopia, Oxford: Basil Blackwell.

Oates, Wallace and Schwab, Robert (1988), Economic Competition among Jurisdictions: Efficiency Enhancing or Distortion Inducing, Journal of Public Economics, 35, 333-354.

Oi, Walter (1973), Workmen's Compensations and Industrial Safety, Supplemental Studies for the National Commission on State Workmen's Compensation Laws, Volume I, Washington, DC: US GPO, 41-106.

Pahre, Robert (1998), Comments on Conference Version of Paper: Labor Standards, Trade Sanctions and the Hijacking Hypothesis, comments on Chapter 12 in Deardorff and Stern, eds., 1998.

Panagariya, Arvind (2001a), Trade Labor Link: A Post-Seattle Analysis, in Drabek, Zdenek, ed., Globalization under Threat: The Stability of Trade Policy and Multilateral Agreements, Cheltenam, UK: Edward Elgar, 101-123.

Panagariya, Arvind (2001b), Labor Standards and Trade Sanctions: Right End Wrong Means, paper presented at the conference, Towards An Agenda for Research on International Economic Integration and Labor Markets, January 15-16, 2001, East-West Center, Hawaii.

Pattanaik, Prasanta (1999), Individual Rights and Social Choice, Public Lecture delivered at Deakin University, Victoria, Australia, November.

Piore, Michael (1990), Labor Standards and Business Strategies, in Labor Standards and Development in the Global Economy, Stephen Herzenberg and Jorge Perez-Lopez, eds., Washington, DC: US Department of Labor, Bureau of International Affairs.

Piore, Michael (1994), International Labor Standards and Business Strategies, in US Department of Labor.

Portes, A. (1990), When More can be Less: Labor Standards, Development, and the Informal Economy, in Labor Standards and Development in the Global Economy, U.S. Department of Labor, Washington, D.C.

Ray, Debraj (1993), Nutrition, Adaptation and Labor Markets, in P.Bardhan, M. DattaChaudhuri and T.N. Krishnan (eds.), Essays in Honour of K.N. Raj, Delhi: Oxford University Press.

Ray, Debraj (1998), Development Economics, Princeton: Princeton University Press.

Ray, Debraj and Streufert, Peter (1993), Dynamic Equilibria with Unemployment due to Undernourishment, Economic Theory, 3, 61-85. 
Raynauld, André and Vidal, Jean-Pierre (1998), Labour Standards and International Competitiveness: A Comparative Analysis of Developing and Industrialized Countries, Northampton, MA: Edward Elgar.

Revesz, Richard (1992), Rehabilitating Interstate Competition: Rethinking the "Race-tothe Bottom" Rationale for Federal Environmental Regulation, New York University Law Review, 67, 1220-1254.

Rodrik, Dani (1996), Labor Standards in International Trade: Do They Matter and What Do We Do About Them?, in Robert Lawrence, Dani Rodrik, and John Whalley, Emerging Agenda for Global Trade: High Stakes for Developing Countries, Washington, DC: Overseas Development Council.

Rosen, Sherwin (1986), The Theory of Equalizing Differences, Chapter 12 in Handbook of Labor Economics, Volume I, eds., Orley Ashenfelter and Richard Layard, Amsterdam: North Holland.

Rothstein, Richard (1994), The Case for Labor Standards, Boston Review, 20,1, December -January.

Sachs, Jeffrey (1997), Re-Thinking International Labor Standards, Lecture, January 22.

Sen, Amartya (1970), The Impossibility of a Paretian Liberal, Journal of Political Economy, 78, 152-157.

Sen, Amartya (1985a), Commodities and Capabilities, Amsterdam: North Holland.

Sen, Amartya (1985b), Well-being, Agency and Freedom: The Dewey Lectures 1984, Journal of Philosophy, 82, 169-221.

Sen, Amartya (1997), On Economic Inequality, Expanded Edition, Oxford: Clarendon Press.

Sengenberger, Werner and Campbell, Duncan (eds.), (1994), International Labour Standards and Economic Interdependence, International Institute for Labour Studies, Geneva.

Shapiro, Carl (1982), Consumer Information, Product Quality, and Seller Reputation, Bell Journal of Economics, Spring.

Singh, Nirvikar (1994), Some Aspects of Technological Change and Innovation in Agriculture, in Agrarian Questions, Kaushik Basu, ed., New Delhi: Oxford University Press.

Singh, Nirvikar and Ravi Thomas (2000), Welfare Policy: Cash Versus Kind, SelfSelection and Notches, Southern Economic Journal, 66, 4, April, 976-990. 
Srinivasan, T.N. (1994), International Labor Standards Once Again!, in US Department of Labor.

Srinivasan, T.N. (1996), International Trade and Labour Standards from an Economic Perspective, in van Dijk and Faber, eds.

Srinivasan, T.N. (1998), Developing Countries and the Multilateral Trading System: From the GATT to the Uruguay Round and the Future, Boulder CO: Westview Press.

Srinivasan, T.N. (1998), Trade and Human Rights, Chapter 12 in Deardorff and Stern, eds., 1998.

Staiger, Robert W. (2001), The International Organization and Enforcement of Labor Standards (this volume).

Stern, Robert (2000), Labor Standards and Trade, Discussion Paper No. 457, Research Seminar in International Economics, School of Public Policy, University of Michigan.

Stiglitz, Joseph (2000), The Contributions of the Economics of Information to Twentieth Century Economics, Quarterly Journal of Economics, 115, 4, November, 1441-1478.

Suzumura, Kotaro (1999), Consequences, Opportunities and Procedures, Social Choice and Welfare, 16, 17-40.

Swinnerton, Kenneth and Rogers, Carol (1999), The Economics of Child Labor: Comment, American Economic Review, 89, 5, 1382-1385.

Thaler, Russell and Rosen, Sherwin (1975), The Value of Saving a Life: Evidence from the Labor Market, in Nestor Terleckyj, ed., Household Production and Consumption, Studies in Income and Wealth, Volume 40, NBER, New York: Columbia University Press.

Tiebout, Charles (1956), A Pure Theory of Local Public Expenditures, Journal of Political Economy, 64, 416-424.

US Department of Labor (1994), International Labor Standards and Global Economic Integration: Proceedings of a Symposium, Washington DC: US Department of Labor.

van Dijk, Pitou and Gerrit Faber, eds. (1996), Challenges to the New World Trade Organization, The Hague: Kluwer Law International.

Weitzman, Martin (1974), Prices vs. Quantities, Review of Economic Studies, October.

Wilson, John D. (1996), Capital Mobility and Environmental Standards: Is There a Theoretical Basis for a Race to the Bottom?, in Bhagwati and Hudec, eds., 1996a.

Zodrow, G. R., and Mieszkowski, Peter (1986), Pigou, Tiebout, Property Taxation, and the Underprovision of Local Public Goods, Journal of Urban Economics, 19, 356-370. 